\title{
EROSIVIDADE DAS CHUVAS ASSOCIADA A PERÍODOS DE RETORNO E PROBABILIDADE DE OCORRÊNCIA NO ESTADO DO RIO DE JANEIRO ${ }^{(1)}$
}

\author{
Roriz Luciano Machado ${ }^{(2)}$, Daniel Fonseca de Carvalho $\left({ }^{3)}\right.$, Janaina Ribeiro Costa \\ Rouws $^{(4)}$, Daniela Pinto Gomes ${ }^{(5)}$ \& Eliete Nazare Eduardo ${ }^{(6)}$
}

\begin{abstract}
RESUMO
O conhecimento da erosividade das chuvas associada à probabilidade de ocorrência e ao período de retorno pode contribuir para o planejamento conservacionista de uma região, em médio e longo prazo. A fim de gerar informações para melhor utilizar modelos e controle da erosão, dados de chuvas de 30 séries pluviográficas e pluviométricas, abrangendo 25 municípios, entre 1933 e 2006, foram estudados quanto à adequação das séries e do cálculo da probabilidade de ocorrência teórica (P) e período de retorno (T) da erosividade das chuvas $\left(\mathrm{EI}_{30} \mathrm{e}\right.$ KE >25), para o Estado do Rio de Janeiro. Foi feita a espacialização do potencial erosivo associado aos períodos de retorno de $2,5,10,20,50$ e 100 anos para todo o Estado. A erosividade anual média $\left(\mathbf{E I}_{30}\right)$ ou fator $\mathbf{R}$ da USLE para qualquer localidade no Estado do Rio de Janeiro pode ser igualada ou superada pelo menos uma vez, em média, em um período de 1,8 a 2,1 anos, com faixa de 48,5 a 54,9\% de probabilidade de ocorrência teórica. As localidades que apresentam maior erosividade associada aos períodos de retorno estão situadas nas mesorregiões Metropolitanas e em partes das mesorregiões Sul e Centro Fluminense. Foi possível identificar de oito a 12 regiões homogêneas, quanto à distribuição espacial da erosividade associada aos períodos de retorno de dois para 100 anos no Estado. De modo geral, a maior variação da distribuição espacial da erosividade apresenta-se na faixa de período de retorno de dois a cinco anos.
\end{abstract}

Termos de indexação: conservação do solo, USLE, recorrência da erosividade.

\footnotetext{
(1) Parte da Tese de Doutorado do primeiro autor apresentada ao Curso de Pós-Graduação em Agronomia-Ciência do Solo, Universidade Federal Rural do Rio de Janeiro - UFRRJ. Recebido para publicação em 13 de dezembro de 2011 e aprovado em 14 de janeiro de 2013.

(2) Professor no Instituto Federal de Educação, Ciência e Tecnologia Goiano, Câmpus Ceres, Rod. 154, Km 03. Caixa Postal 51. CEP 76300000 Ceres (GO). E-mail: roriz.machado@ifgoiano.edu.br

(3) Professor, UFRRJ. km 07, BR 465. CEP 23890-000 Seropédica (RJ). E-mail: carvalho@pq.cnpq.br

(4) Pesquisadora, Embrapa Agrobiologia. BR 465, km 07. CEP 23890-000 Seropédica (RJ). E-mail: janaina@cnpab.embrapa.br

(5) Doutoranda em Agronomia, Fitotecnia, UFRRJ. E-mail: danielagomesagro@hotmail.com

(6) Eng. Agrônoma, Mestre em Agronomia-Ciência do Solo - UFRRJ. E-mail: elietenazare@gmail.com
} 


\title{
SUMMARY: RAINFALL EROSIVITY ASSOCIATED TO RETURN PERIODS AND OCCURRENCE PROBABILITY IN THE STATE OF RIO DE JANEIRO, BRAZIL
}

\begin{abstract}
Knowledge on rainfall erosivity associated to occurrence probability and return periods can contribute to conservation planning in the medium and long term. With the objective of generating information for a better use of medium and long-term erosion models and erosion control, rainfall data of 30 pluviometric and pluviographic data sets from 25 cities ranging from 1933 to 2006 were studied in terms of adjustment of data sets, calculation of the probability of theoretical occurrence $(P)$ and return period ( $T$ ) of rainfall erosivity $\left(E I_{30}\right.$ and $\left.K E>25\right)$ for the State of Rio de Janeiro, as well as the spatialization of erosivity associated to return periods of $2,5,10,20,50$, and 100 years for the whole state. Average annual erosivity $\left(E I_{30}\right)$, or " $R$ " factor of USLE, for any location in the state of Rio de Janeiro, can on average be equaled or surpassed at least once in a 1.8-2.1 year period, at a theoretical occurrence probability of 48.5 to $54.9 \%$. The locations with highest erosivity rates associated to return periods are located in the Metropolitan mesoregions as well as in parts of the South and Center Mesoregions. It was possible to identify 8-12 homogeneous regions of spatial distribution of erosivity associated to the return periods of 2-100 years in the state of Rio de Janeiro. In general, the variation of spatial distribution of erosivity was highest in a return period ranging from two to five years.
\end{abstract}

Index terms: soil conservation, USLE, erosivity return period.

\section{INTRODUÇÃO}

Em todo o mundo é cada vez mais frequente a erosão do solo, em vários graus de intensidade, o que gera danos em diferentes abordagens e impõe crescente desafio à pesquisa em caracterizar e prever a influência dos diferentes fatores causadores do fenômeno, bem como, o uso das informações geradas no desenvolvimento de tecnologias preventivas e corretivas de conservação de solo e água.

Fundamentalmente, a erosão hídrica é definida como o resultado dos processos de desagregação de partículas do solo, transporte e deposição dessas partículas (unitárias e agregadas) em razão da ação do impacto da gota de chuva e o escoamento superficial da água sobre o solo (Ellison, 1947). Segundo Hudson (1973) e Wischmeier \& Smith (1978), os principais fatores da erosão hídrica estão relacionados a clima, solo, relevo, cobertura e uso do solo e práticas conservacionistas.

A chuva é considerada o fator climático que mais influencia a erosão do solo, especialmente nos trópicos por causa das suas características, sobretudo relacionadas ao volume precipitado e à sua distribuição temporal e espacial (Hudson, 1995). A energia cinética da chuva representa o efeito do impacto da gota de chuva diretamente sobre o solo, que contribui para a erosão, em razão do desprendimento de partículas do solo no local do impacto, no transporte por salpicamento das partículas desprendidas e na produção de energia na forma de turbulência à água da superfície, constituindo o estádio inicial da erosão hídrica (Duley, 1939; Ellison, 1947). De acordo com Wischmeier \& Smith (1958) e Wischmeier (1959), o produto da energia cinética pela intensidade das chuvas em 30 min é o melhor índice para estimar a erosividade, sendo utilizado na obtenção do fator $\mathrm{R}$ da Equação Universal de Perda de Solo - USLE. Desse modo, o produto entre a energia cinética (Ec) e intensidade máxima em 30 $\min \left(\mathrm{I}_{30}\right)$ representa um termo de interação que mede o efeito de como o salpico e a turbulência se combinam com a enxurrada para desagregar e transportar as partículas desprendidas do solo (Bertoni \& Lombardi Neto, 1990).

A utilização do $\mathrm{EI}_{30}$, no entanto, passou a ser discutida para países tropicais onde a intensidade das chuvas pode ultrapassar $150 \mathrm{~mm} \mathrm{~h}^{-1}$, sendo propostos, em razão disso, índices alternativos como o $\mathrm{KE}>25$ (Hudson, 1995) entre outros. Esse índice considera a energia cinética total das chuvas que apresentam intensidades de precipitação superiores a $25 \mathrm{~mm} \mathrm{~h}^{-1}$. De acordo com Lal (1976), o índice $\mathrm{KE}>25$ é mais fácil de ser determinado, uma vez que dispensa o uso da intensidade máxima em 30 min. No entanto, em várias localidades estudadas no Brasil, não foi encontrada diferença estatística com o índice $\mathrm{EI}_{30}$ (Marques et al., 1997), sendo esse último, recomendado por ser o índice oficial da USLE.

É comum no Brasil a escassez de dados pluviográficos e, ou, falta de séries históricas adequadas para se obterem índices de erosividade (Carvalho et al., 2005). Além da carência de informações, o intenso trabalho, necessário desde a leitura das informações de pluviogramas até o cálculo dos índices de erosividade, contribuiu para a busca de alternativas como a possibilidade de obtenção desses índices a partir de características pluviométricas (Bertoni \& Lombardi Neto, 1990), como a altura precipitada e o coeficiente de chuva (Rc) (Fournier, 1956, modificado por Lombardi Neto, 1977). Outra situação comum nesse tipo de estudo é o fato de a estação meteorológica apresentar série pluviográfica 
com poucos anos de registro e série pluviométrica com muitos anos de medição, o que torna oportuno aproveitar esses dados para ampliar a série pluviográfica, após estudo de correlação entre ambas para a mesma estação meteorológica ou estação vizinha. Estudos dessa natureza foram desenvolvidos por Roque et al. (2001), para Piraju, SP, Colodro et al. (2002), para Teodoro Sampaio, SP, e Gonçalves et al. (2006), para o Estado do Rio de Janeiro.

Carvalho et al. (1989) e Moreti et al. (2003b), visando planejamento conservacionista em médio e longo prazo, relataram que o uso de índices de erosividade associado a períodos de retorno pode ser útil para solucionar problemas específicos relacionados a aspectos econômicos e ecológicos e dos possíveis danos admitidos, por ser mais consistente que simplesmente a erosividade média anual ou fator $\mathrm{R}$ da USLE. Além disso, a avaliação dos períodos de retorno e da probabilidade de ocorrência da erosividade anual das chuvas possibilita criar previsões da frequência com que as estimativas de perdas de solo são sub ou superestimadas (Cassol et al., 2008).

Diversos estudos sobre período de retorno da erosividade das chuvas foram desenvolvidos em diferentes localidades, podendo ser citados os trabalhos de Dias \& Silva (2003), para Fortaleza, CE; Peñalva Bazzano et al. (2007), para Quaraí, RS; Peñalva Bazzano et al. (2010), para Rio Grande, RS; Carvalho et al. (1989), para Mococa, SP; Roque et al. (2001), para Piraju, SP; Colodro et al. (2002), para Teodoro Sampaio, SP; Moreti et al. (2003a), para São Manuel, SP; Moreti et al. (2003b), para Pedrinhas Paulista, SP; e Evangelista et al. (2006), para Lavras, MG. No Estado do Rio de Janeiro pode ser citado o trabalho realizado por Carvalho et al. (2010), para Seropédica.

Ao contrário de trabalhos individualizados a delimitação da erosividade para várias localidades, associada ao período de retorno e a sua espacialização, pode disponibilizar importantes informações para o planejamento conservacionista de uma região, principalmente aquelas que apresentam condições de forte declividade e altos índices pluviométricos como o Estado do Rio de Janeiro. Os objetivos deste trabalho foram caracterizar a probabilidade de ocorrência teórica e período de retorno da erosividade das chuvas para diferentes localidades no Estado do Rio de Janeiro; e espacializar a erosividade das chuvas associada a diferentes períodos de retorno para o Estado.

\section{MATERIAL E MÉTODOS}

Este trabalho foi realizado com dados de 30 estações pluviográficas disponibilizados pelas entidades: Agência Nacional de Águas (ANA, 2009), Instituto Nacional de Meteorologia (INMET), Serviços e Eletricidade S/A(LIGHT), Departamento Nacional de
Obras de Saneamento (DNOS) e Superintendência Estadual de Rios e Lagoas (SERLA, atual INEA), abrangendo 25 municípios e cinco das seis mesorregiões do Estado do Rio de Janeiro (Quadro 1 e Figura 1).

As chuvas foram individualizadas, utilizando critérios adotados por Cabeda (1976), que considera uma chuva individual, quando essa estiver separada de outra por no mínimo $6 \mathrm{~h}$, com precipitação pluvial inferior a $1 \mathrm{~mm}$; e, erosivas, quando a altura precipitada é superior a $10 \mathrm{~mm}$, ou quando igual ou superior a $6 \mathrm{~mm}$, em um período máximo de $15 \mathrm{~min}$. Em seguida, os dados foram submetidos ao software CHUVEROS (programa elaborado pelo professor Elemar Antônino Cassol), para o cálculo dos índices de erosividade $\mathrm{EI}_{30}$ e $\mathrm{KE}>25$.

Utilizaram-se também para o cálculo desses índices, séries pluviométricas localizadas no mesmo posto das estações pluviográficas ou vizinhas a essas, obtidas da base de dados Hidroweb/ANA, para substituição de séries pluviográficas de baixa qualidade (Quadro 1). Para estimativa desses índices, foram utilizadas equações obtidas por Gonçalves (2002) e Montebeller (2005), que ajustaram modelos entre os índices de erosividade, oriundos de pluviógrafo e precipitação pluvial mensal média ( $p$ ) ou fator chuva - Rc (Fournier, 1956, modificado por Lombardi Neto, 1977), para igual período entre as séries. O critério adotado sobre qual equação utilizar baseou-se na estação de maior valor de coeficiente de determinação $\left(R^{2}\right)$, verificando, em seguida, a qualidade do valor estimado, como ausência de valores negativos.

Para validar o uso das equações na estimativa dos índices de erosividade para séries com maior número de anos que os que deram origem a essas, ainda que no mesmo posto meteorológico, foi aplicada a análise de intervalo de confiança (IC), conforme Moreti et al. (2003a), para determinar o máximo de anos possível em que a altura precipitada $(\mathrm{mm})$ obtida da série pluviométrica fosse estatisticamente semelhante à altura precipitada na série pluviográfica disponível (série menor). Isso foi realizado de forma gráfica, sendo analisada a sobreposição dos intervalos de confiança de ambas as séries, após as tentativas necessárias, variando o tamanho da série pluviométrica disponível. Com essa análise, 18 estações pluviométricas foram utilizadas na estimativa dos índices de erosividade, em substituição às séries pluviográficas com poucos anos e com falhas. Moreti et al. (2003a) obtiveram resultados satisfatórios com a utilização da técnica de análise de IC para avaliar a adequação do uso de equação desenvolvida para a região de Mococa, SP, com base no coeficiente de chuva (Rc), visando estimar dados de erosividade em São Manoel, SP.

Em relação ao período e tamanho das séries históricas, após estudo de adequação, não foi possível estabelecer período comum para todas as séries selecionadas, que variaram de 1933 a 2006 . A média de anos das séries de cada mesorregião foi de 16 anos 
Quadro 1. Identificação das séries pluviométricas/pluviográficas estudadas, de acordo com Brasil (2009)

\begin{tabular}{|c|c|c|c|c|c|c|c|}
\hline Código & Nome & Resp. & Município & Lat. & Long. & Alt.(m) & $\begin{array}{l}\text { Série utilizada } \\
\text { (tamanho) }\end{array}$ \\
\hline \multicolumn{8}{|c|}{ Mesorregião Baixadas Litorâneas } \\
\hline 02242101 & Rio Mole $\mathrm{e}^{(1)}$ & SERLA & Saquarema & $-22,8531$ & $-42,5519$ & 10 & 1979-1994 (16) \\
\hline \multicolumn{8}{|c|}{ Mesorregião Centro Fluminense } \\
\hline 02142014 & Paquequer ${ }^{(1,2)} /$ Carmo & ANA & Carmo & $-21,8778$ & $-42,6422$ & 150 & 1977-2006 (30) \\
\hline 2242031 & Cordeiro $^{(1)}$ & ANA & Cordeiro & $-22,0333$ & $-42,3500$ & 480 & 1947-1965 (19) \\
\hline 02142059 & Usina Ilha dos Pombos ${ }^{(3)}$ & LIGTH & Carmo & $-21,8433$ & $-42,5783$ & 146 & 1979-1989; e 1991 (12) \\
\hline \multirow[t]{2}{*}{02242023} & Conselheiro Paulino ${ }^{(1,2)} /$ & & & & & & \\
\hline & Nova Friburgo & ANA & Nova Friburgo & $-22,2167$ & $-42,5167$ & 830 & $1960-1970(11)$ \\
\hline 02142016 & Sta M. Madalena ${ }^{(1)}$ & ANA & Sta M. Madalena & $-21,9500$ & $-42,0167$ & - & 1966-1979 (14) \\
\hline \multicolumn{8}{|c|}{ Mesorregião Metropolitana } \\
\hline 02243235 & Andorinhas $^{(3)}$ & SERLA & Magé & $-22,5433$ & $-43,0603$ & 60 & $1977-1996(20)$ \\
\hline 02242095 & Cachoeiras de Macacu $^{(3)}$ & SERLA & Cachoeiras de Macacu & $-22,4794$ & $-42,6578$ & 40 & 1979-1993 (15) \\
\hline 02243239 & Capela Mayrink $^{(3)}$ & SERLA & Rio de Janeiro & $-22,9578$ & $-43,2778$ & 460 & 1980-1995 (16) \\
\hline 02243186 & Ecologia Agrícola $^{(1)}$ & INMET & Seropédica & $-22,7667$ & $-43,6833$ & 33 & $1973-2002(30)$ \\
\hline 02243083 & Eletrobrás ${ }^{(1)}$ & SERLA & Rio de Janeiro & $-22,9217$ & $-43,4200$ & 40 & 1969-1994 (26) \\
\hline 02242094 & Escola União ${ }^{(3)}$ & SERLA & Magé(4) & $-22,5842$ & $-42,9408$ & 10 & 1977-1994 (19) \\
\hline 02242100 & Fazenda Coqueiro $^{(3)}$ & SERLA & Teresópolis & $-22,4283$ & $-42,8008$ & 140 & 1978-1993 (16) \\
\hline 02242096 & Fazenda Sto Amaro ${ }^{(3)}$ & SERLA & Cachoeiras de Macacu & $-22,4108$ & $-42,7236$ & 260 & 1977-1995 (19) \\
\hline 02242014 & Japuíba $^{(1)}$ & ANA & Cachoeiras de Macacu & $-22,5592$ & $-42,6989$ & 50 & 1967-2005 (39) \\
\hline 02242098 & Posto Garrafão ${ }^{(3)}$ & SERLA & Magé(4) $^{(4)}$ & $-22,4822$ & $-42,9961$ & 640 & 1980-1995 (16) \\
\hline 02242097 & Sambaetiba $^{(3)}$ & SERLA & Itaboraí & $-22,6394$ & $-42,8006$ & 10 & 1977-1995 (19) \\
\hline 02242091 & Tanguá(3) & SERLA & Rio Bonito & $-22,7081$ & $-42,7042$ & 40 & 1980-1995 (16) \\
\hline 02243151 & Vassouras $^{(1)}$ & INMET & Vassouras & $-22,4167$ & $-43,6667$ & 437 & $1961-1978(18)$ \\
\hline 02243238 & Xerém ${ }^{(3)}$ & SERLA & Duque de Caxias & $-22,5508$ & $-43,3042$ & 143 & 1977-1995 (19) \\
\hline \multicolumn{8}{|c|}{ Mesorregião Norte Fluminense } \\
\hline \multirow[t]{2}{*}{02241001} & Farol de São Tomé(1,2)/ & & & & & & \\
\hline & Campos & ANA & Campos & $-22,0425$ & $-41,0556$ & 2 & 1991-2006 (16) \\
\hline 02241010 & Quiçamã $^{(1,2)} /$ Macaé & DNOS & Macaé(5) & $-22,1000$ & $-41,4667$ & - & $\begin{array}{c}1945-1955 ; \\
1967-1980(25)\end{array}$ \\
\hline \multicolumn{8}{|c|}{ Mesorregião Sul Fluminense } \\
\hline 02243008 & Manuel Duarte ${ }^{(1)}$ & ANA & Rio das Flores & $-22,0858$ & $-43,5567$ & 396 & 1977-2006 (30) \\
\hline 02243165 & Pirai $^{(1)}$ & INMET & Piraí & $-22,6333$ & $-43,8833$ & 388 & 1961-1978 (18) \\
\hline 02244030 & Nhangapi ${ }^{(1,2)} /$ Resende & ANA & Resende & $-22,5033$ & $-44,6156$ & 440 & 1957-2005 (49) \\
\hline \multirow[t]{2}{*}{02243211} & Barragem de Lajes ${ }^{(1,2)} /$ & & & & & & \\
\hline & Ribeirão das Lajes & LIGTH & Piraí & $-22,7008$ & $-43,8783$ & 462 & $1942-1978(37)$ \\
\hline 02243205 & Elevat. Santa Cecília ${ }^{(1)}$ & LIGTH & Barra do Piraí & $-22,4819$ & $-43,8392$ & 371 & 1933-2003 (71) \\
\hline 02244033 & Sta Isabel do Rio Preto ${ }^{(1)}$ & ANA & Valença & $-22,2311$ & $-44,0647$ & 567 & 1973-2006 (34) \\
\hline 02244103 & Barragem de Tocos ${ }^{(3)}$ & LIGTH & Rio Claro & $-22,7489$ & $-44,1247$ & 453 & $\begin{array}{c}\text { 1981-1988; } \\
1993-1999(15)\end{array}$ \\
\hline 02344016 & Vila Mambucaba $^{(1)}$ & ANA & Angra dos Reis & $-23,0258$ & $-44,5181$ & - & 1983-2006 (24) \\
\hline
\end{tabular}

(1) Dados pluviométricos; ${ }^{(2)}$ Pluviométrica localizada próxima e utilizada em substituição à pluviográfica; ${ }^{(3)}$ Dados pluviográficos; (4) Coordenadas descritas por Brasil (2009) rebatem as estações 02242094 e 02242098 para o município de Guapimirim, RJ; e (5) Coordenadas informadas por Brasil (2009) posiciona a estação 02241010 em Quissamã, RJ.

para a mesorregião Baixada Litorânea; 17,2 anos, para a Centro Fluminense; 20,6 anos, para a Metropolitana; 20,5 anos, para a Norte Fluminense; e 34,8 anos, para a Sul Fluminense (Quadro 1).

Conforme Wischmeier \& Smith (1978), para obterse o fator $R$ da USLE de forma confiável são necessários pelo menos 22 anos de dados. No Brasil, a erosividade é determinada com número de anos inferior a essa recomendação, pois é difícil atender a essa exigência, em razão da escassez de dados pluviográficos (Marques et al., 1997).

Após definição do período a ser usado de cada série pluviométrica, foram elaboradas planilhas com as precipitações médias mensais ( $p$ ) e o coeficiente de chuva (Rc) para o mês i e ano j, para cada estação pluviométrica. Utilizando as equações de Gonçalves 


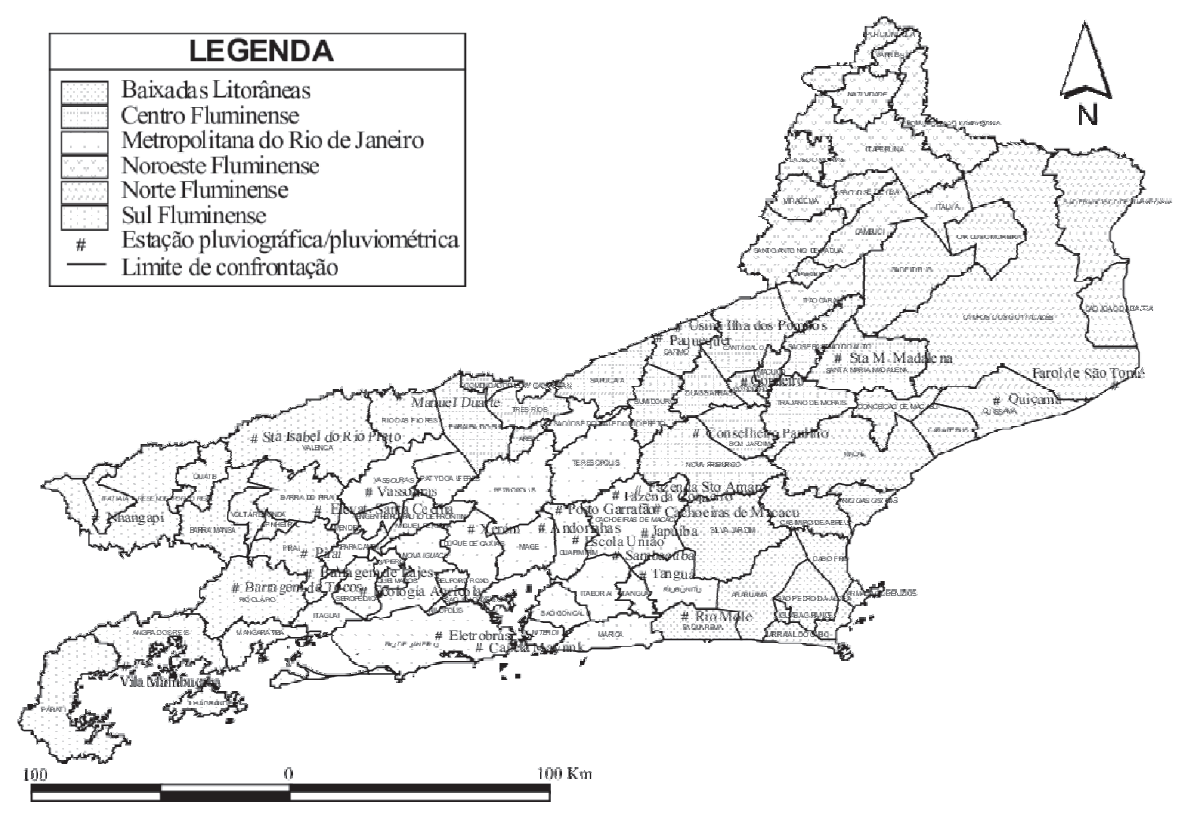

Figura 1. Localização das estações pluviométricas/pluviográficas no Estado do Rio de Janeiro (mapa político administrativo do IBGE).

(2002) e Montebeller (2005) e as planilhas de dados pluviométricos ( $\mathrm{p}$ e Rc), gerou-se nova planilha com índices mensais de erosividade, para cada ano da série, conforme Moreti et al. (2003a), para as estações estudadas, aplicando-se a equação 1 :

$$
E_{i j}=\frac{\left(P_{i j} \cdot E_{i j}\right)}{P a_{i j}}
$$

em que: $\mathrm{E}_{\mathrm{ij}}=$ índice de erosividade do mês $\mathrm{i}$ contido no ano $\mathrm{j}$ da série de dados; $\mathrm{P}_{\mathrm{ij}}=$ total precipitado no mês $\mathrm{i}$ contido em um ano $\mathrm{j}$ da série de dados; $\mathrm{IEij}=$ índice de erosividade $\left(\mathrm{EI}_{30}\right.$ ou $\left.\mathrm{KE}>25\right)$ mensal média, em que o mês i está contido na série de dados; $\mathrm{Pa}_{\mathrm{ij}}=$ precipitação mensal média em que o mês i está contido na série.

O somatório dos índices mensais de erosividade $\left(\mathrm{EI}_{30}\right.$ e $\left.\mathrm{KE}>25\right)$ dentro de cada ano foi usado para o cálculo do índice de erosividade para o ano em questão; o conjunto de todos os anos da série foi utilizado para determinar a probabilidade de ocorrência e o período de retorno, conforme a seguir.

\section{Probabilidade de ocorrência e período de retorno da erosividade das chuvas}

O período de retorno $(\mathrm{T})$ e a probabilidade de ocorrência (Pr) foram obtidos, conforme Villela \& Matos (1975), utilizando as equações 2 e 3, respectivamente:

$$
\mathrm{T}=\frac{\mathrm{N}+1}{\mathrm{~m}}
$$

em que: $\mathrm{N}$ = número de anos da extensão da série parcial de dados; $m$ = número de ordem do índice de erosividade.

$$
\operatorname{Pr}=\frac{100}{\mathrm{~T}}
$$

Nas equações 2 e 3, T é expresso em anos e Pr, em percentagem.

Com auxílio de uma planilha eletrônica, os valores dos índices de erosividade anuais médios de cada estação foram dispostos em ordem decrescente e associados a um valor de ordem. Devido ao fato de trabalhos anteriores terem sido desenvolvidos usando a função Log-normal (Moreti et al., 2003a; Evangelista et al., 2006), típica de eventos hidrológicos (Roque et al., 2001), foi realizado inicialmente, ajuste para essa distribuição. Para isso, foi estimado o valor do coeficiente de frequência $(Z)$, utilizando a equação 4:

$$
\mathrm{Z}=\frac{\log (\mathrm{IE})-\overline{\mathrm{IE}} \mathrm{I}}{\mathrm{DPl}}
$$

em que: $\mathrm{IE}=$ índice de erosividade; $\overline{\mathrm{IE}} \mathrm{l}=$ média do logaritmo dos valores de IE; DPl = desvio-padrão do logaritmo dos valores de IE.

Em seguida, foram estimados valores teóricos de probabilidade (Prt), por meio da função distribuição de probabilidade Log-normal, utilizando-se o aplicativo Excel.

$$
\operatorname{Prt}=\frac{1}{\mathrm{IE} \cdot \mathrm{DP} \sqrt{2 \pi}} \mathrm{E} \frac{\frac{-(\ln (\mathrm{IE})-\overline{\mathrm{IE}})^{2}}{2 \mathrm{DP}^{2}}}{}
$$

em que: $\overline{\mathrm{I}} \overline{\mathrm{E}}=$ média dos valores de IE; DP = desviopadrão dos valores de IE. 


\section{Avaliação do ajuste dos dados de chuvas à distribuição Log-Normal}

A fim de verificar o ajuste dos dados à distribuição Log-Normal, foi utilizado o teste de aderência de Kolmogorov-Smirnov (K-S), a $5 \%$, conforme Evangelista et al. (2006). Para cada valor de ordem foi estimada a diferença entre o valor de probabilidade calculado pela equação 3 e o valor teórico obtido pela equação 5. Finalmente, com base nos valores teóricos de probabilidade, do período de retorno e dos índices de erosividade, foram confeccionadas, no ambiente MatLab, curvas e equações de ajuste linear (Figuras 2 a 9), possibilitando, assim, a estimativa dos índices
$\mathrm{EI}_{30}$ e $\mathrm{KE}>25$, para diferentes valores de período de retorno e probabilidade de ocorrência.

Seguindo o padrão encontrado na literatura (Roque et al., 2001; Moreti et al., 2003a; Evangelista et al., 2006; Almeida et al., 2011), a fim de permitir comparações entre diferentes localidades, foram estimados, para cada estação, índices de erosividade com períodos de retorno de $2,5,10,20,50$ e 100 anos.

\section{Espacialização dos valores de erosividade associada a períodos de retorno}

Para obter a noção geral da iso-ocorrência da erosividade das chuvas no Estado do Rio de Janeiro,

Período de retorno - $\mathrm{T}$, anos

(b)

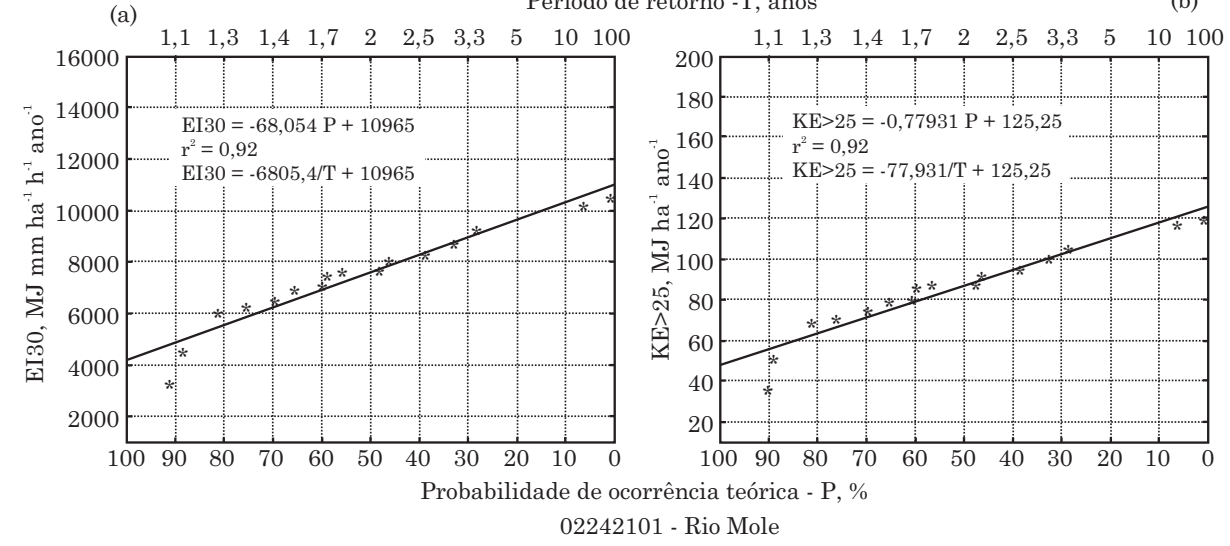

Figura 2. Distribuição da probabilidade de ocorrência (P) e do período de retorno (T) da erosividade das chuvas, por meio dos índices $\mathrm{EI}_{30}$ (a) e KE > 25 (b) anuais para a Mesorregião Baixadas Litorâneas.

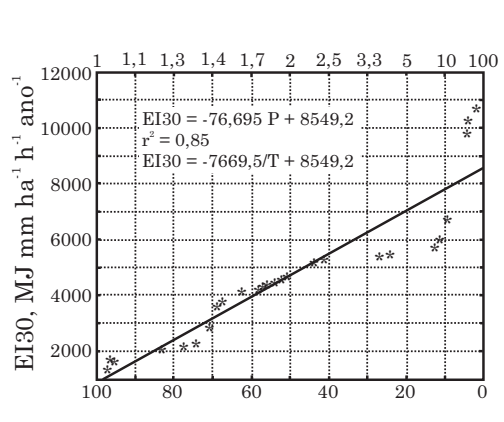

02142014 - Paquequer

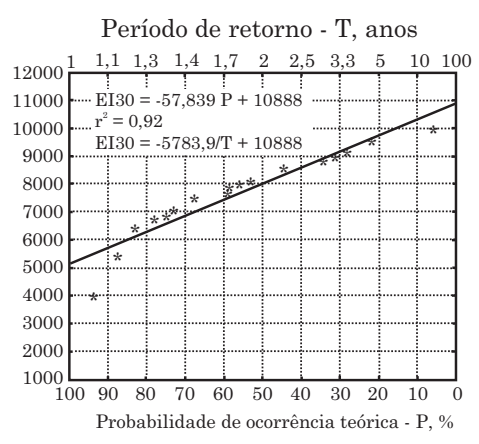

2242031 - Cordeiro

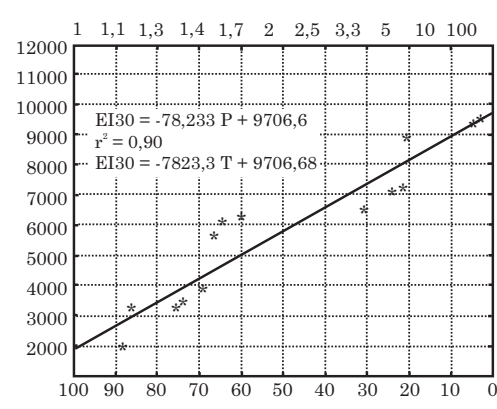

02142059 - Usina Ilha dos Pombos

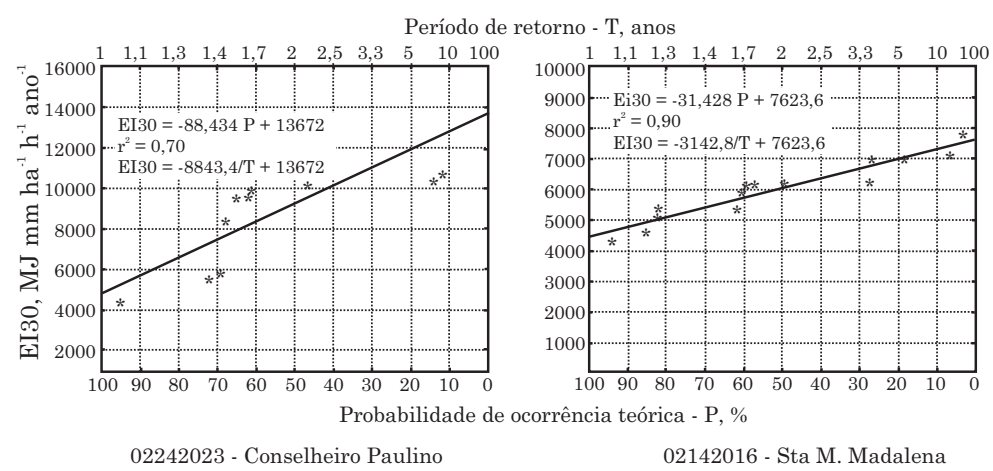

Figura 3. Distribuição da probabilidade de ocorrência (P) e do período de retorno (T) da erosividade das chuvas por meio do índice $\mathbf{E I}_{30}$ anual para as estações localizadas na Mesorregião Centro Fluminense. 


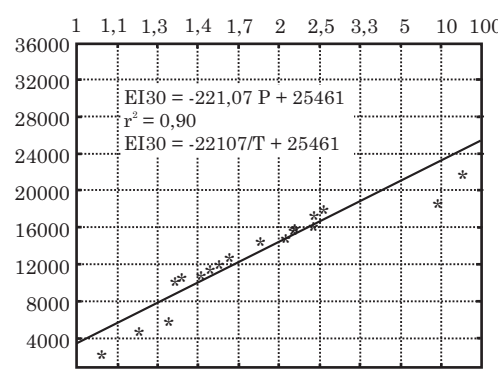

02243235 - Andorinhas

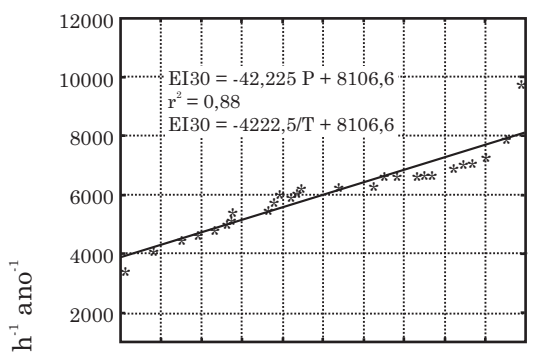

02243186 - Ecologia Agrícola

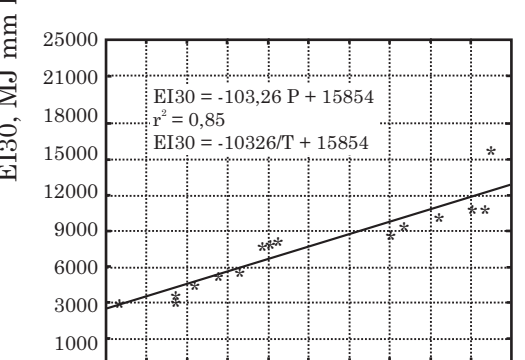

02242100- Fazenda Coqueiro

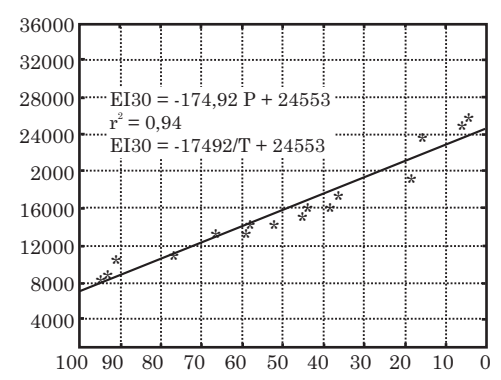

02242098 - Posto Garrafão

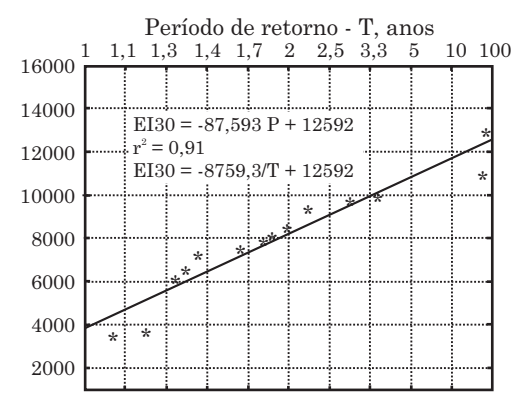

02242095 - Cachoeiras Macacu

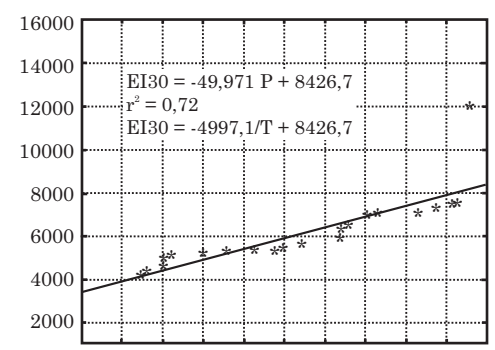

02243083 - Eletrobrás

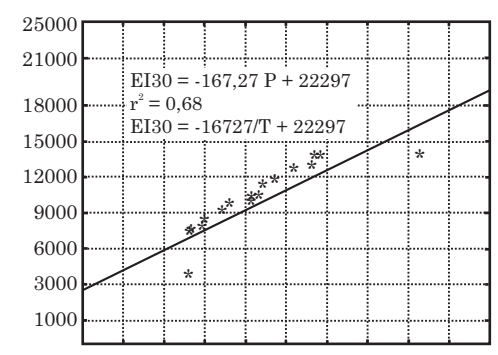

02242096 - Fazenda Santo Amaro

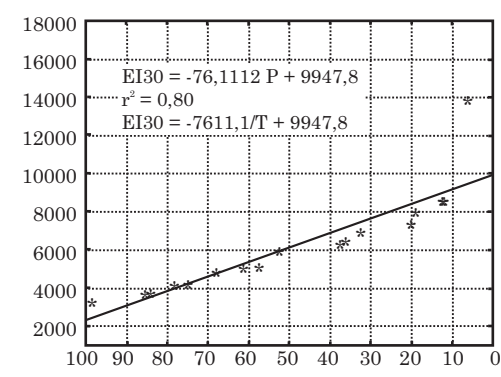

02242097 - Sambaetiba

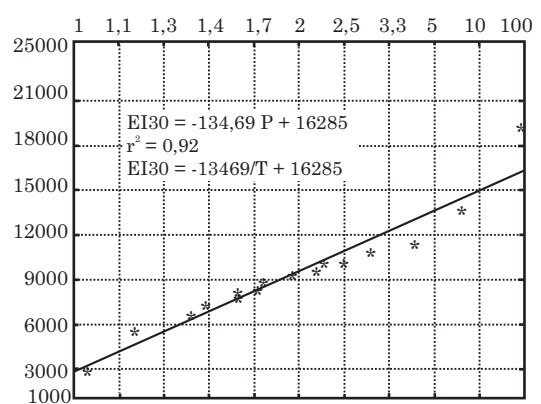

02243239 - Capela Mayrink

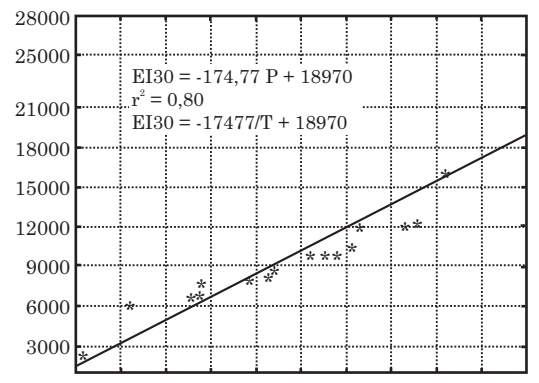

02242094 - Escola União

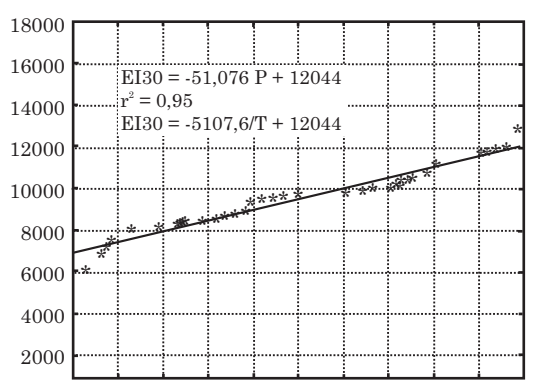

02242014 - Japuíba

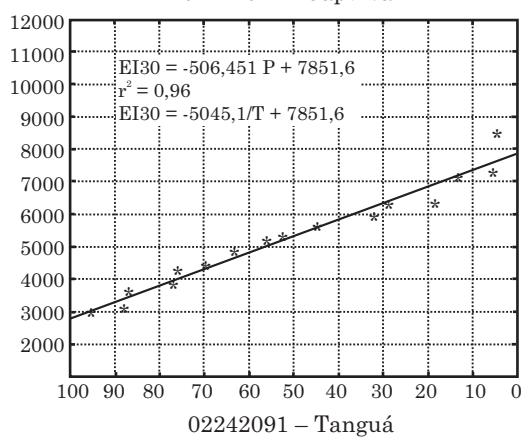

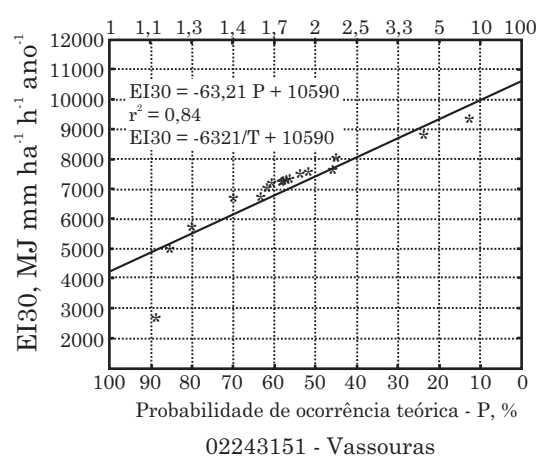

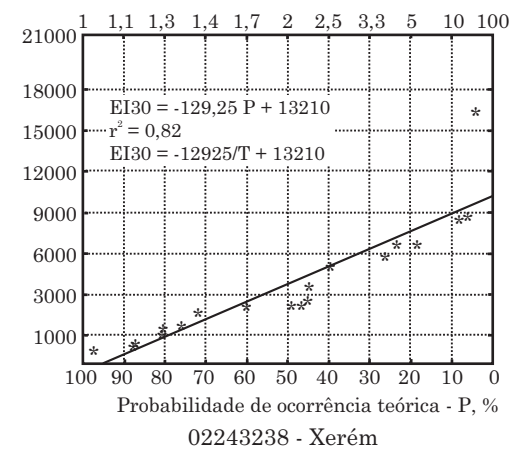

Figura 4. Distribuição da probabilidade de ocorrência (P) e do período de retorno (T) da erosividade das chuvas, pelo índice $\mathrm{EI}_{30}$ anual, para as estações localizadas na Mesorregião Metropolitana. 


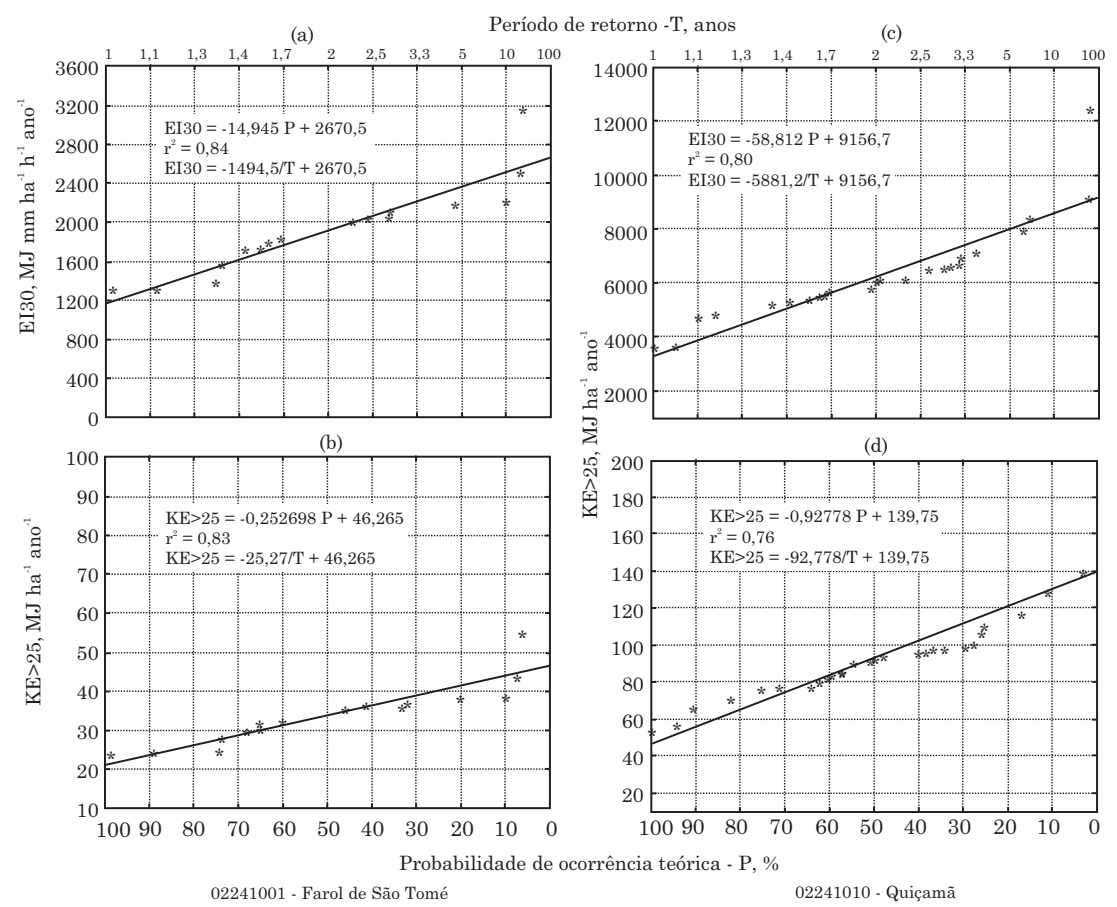

Figura 5. Distribuição da probabilidade de ocorrência (P) e do período de retorno (T) da erosividade das chuvas, pelo índice $\mathrm{EI}_{30}(\mathrm{a}, \mathrm{c})$ e $\mathrm{KE}>25$ (b,d) anuais, para as estações localizadas na Mesorregião Norte Fluminense.

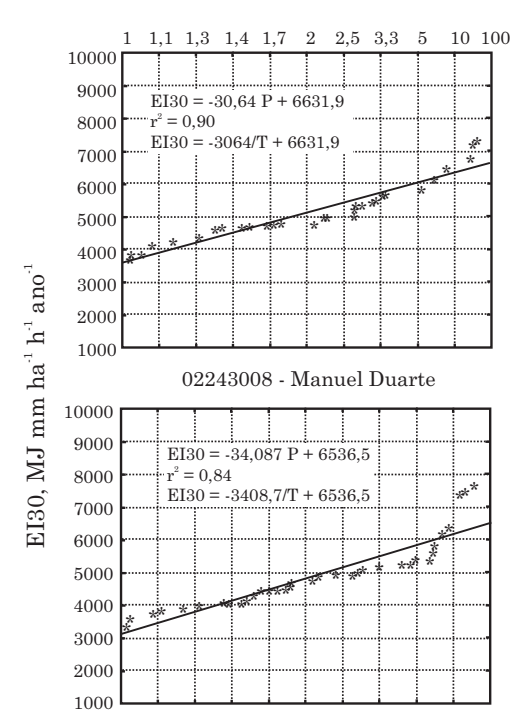

02243211 - Barragem de Lajes

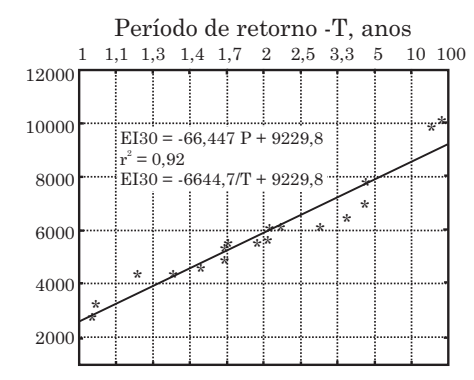

02243165 - Piraí

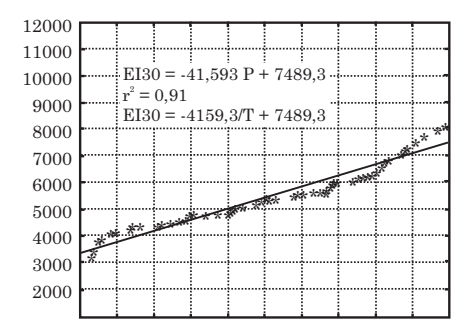

02243205 - Elevat. Santa Cecília

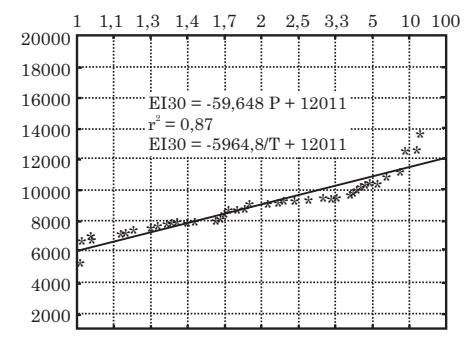

02244030 - Nhangapi

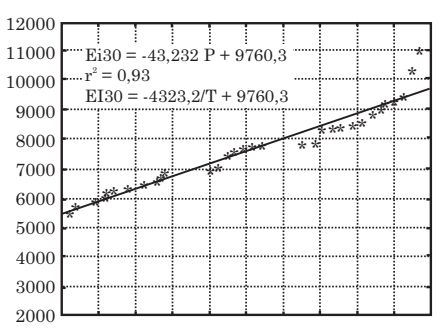

02244033 - Sta Isabel Rio Preto

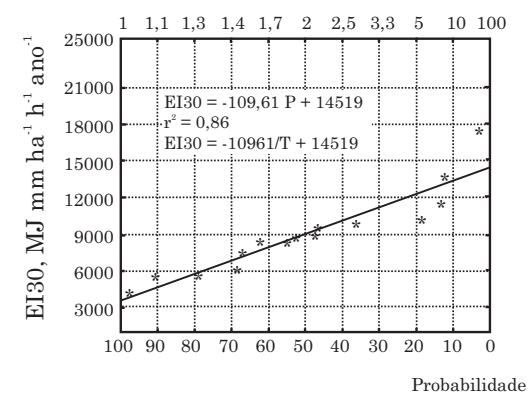

02244103 - Barragem de Tocos

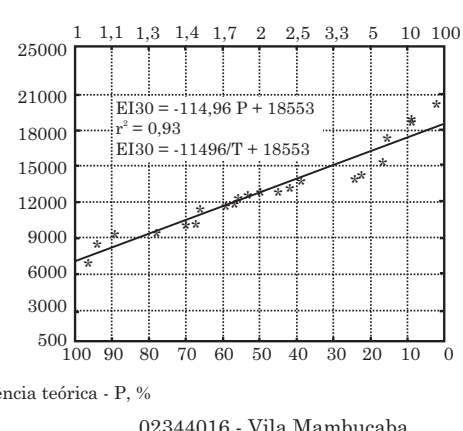

Figura 6. Distribuição da probabilidade de ocorrência (P) e do período de retorno (T) da erosividade das chuvas, pelo índice $\mathrm{EI}_{30}$ anual, para as estações localizadas na Mesorregião Sul Fluminense. 


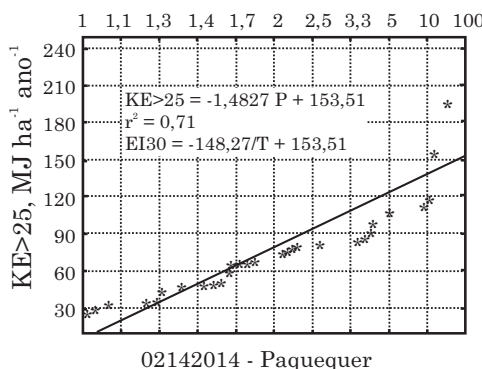

02142014 - Paquequer

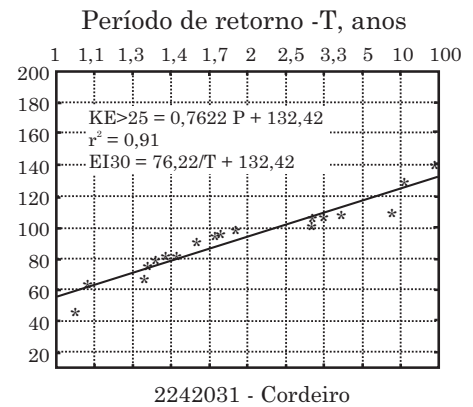

2242031 - Cordeiro

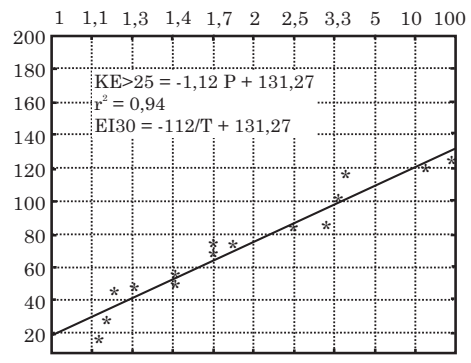

02142059 - Usina Ilha dos Pombos

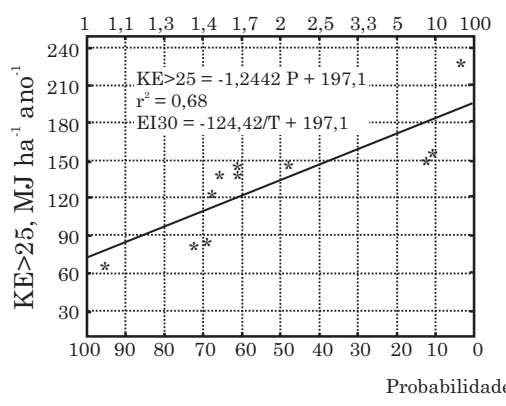

02242023 - Conselheiro Paulino

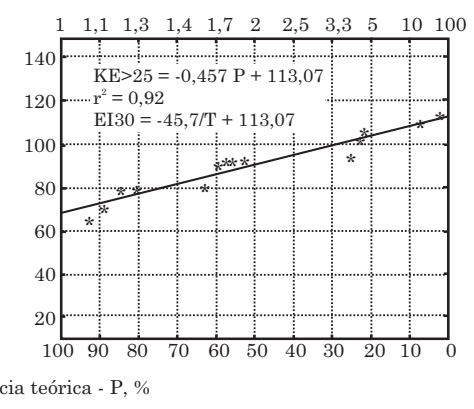

02142016 - Sta M. Madalena

Figura 7. Distribuição da probabilidade de ocorrência (P) e do período de retorno (T) da erosividade das chuvas, medidos pelo índice KE > 25 anual, para estações localizadas na Mesorregião Centro Fluminense.

associada aos diferentes períodos de retorno, foi realizada, para cada período de retorno, a interpolação dos valores sobre base georreferenciada, disponibilizada pelo Instituto Brasileiro de Geografia e Estatística IBGE, com o contorno, "máscara", do Estado, contendo a divisão das mesorregiões e municípios. Essa base, que se encontrava anteriormente no formato shape, foi convertida para o formato grid e submetida à técnica de interpolação do inverso do quadrado da distância, utilizando uma malha de $200 \mathrm{~m}$ e os dados de erosividade associados aos períodos de retorno estudados. Em seguida, foram elaborados os mapas com uso do programa de computação Surfer 8.0.

A interpolação de valores para locais não amostrados, utilizando a técnica do inverso do quadrado da distância, tem sido questionada quando comparada com técnicas de melhor precisão, como a Krigagem (Gotway et al., 1996), apresentando algumas desvantagens como a impossibilidade de geração de mapas de erros e de correlação com outras variáveis (Montebeller et al., 2007). No entanto, para aplicação da Krigagem, é necessário utilizar quantidade mínima de dados (pontos) para que a dependência espacial, caso exista, possa ser expressa. Quando não existe dependência espacial não se justifica a adoção da interpolação por Krigagem. Montebeller (2005) não encontrou dependência espacial ao trabalhar com índices de erosividade $\left(\mathrm{EI}_{30} \mathrm{e} \mathrm{KE}>25\right.$ anuais médios) das chuvas para o Estado do Rio de Janeiro, referentes a 36 estações pluviográficas, muitas em comum com este trabalho. Esse autor conseguiu ajustar semivariogramas quando passou a utilizar informações provenientes de 88 estações, incluindo dados pluviométricos.

\section{RESULTADOS E DISCUSSÃo}

De acordo com o teste de Kolgomorov-Smirnov, verificou-se que todas as estações avaliadas apresentaram ajuste à distribuição Log-Normal, sendo essa adequada para a natureza dos dados. Em relação ao uso de equações com base na precipitação média mensal (p) e no coeficiente de chuva (Rc), essa última evidenciou-se mais adequada na estimativa de $64 \%$ dos índices $\mathrm{EI}_{30}$ e $71 \%$, dos $\mathrm{KE}>25$ (Quadros 2 e 3). O uso do coeficiente Rc para estimativa de $\mathrm{EI}_{30}$ foi também o mais indicado nos estudos de Carvalho et al. (1991), em Mococa, SP; Rufino et al. (1993), em oito regiões no Paraná; e Silva \& Dias (2003), em Fortaleza, CE. No entanto, nos trabalhos de Silva et al. (1997), em Goiânia, e Peñalva Bazzano et al. (2007), em Quaraí, RS, ambos os índices (p e Rc), foram considerados satisfatórios.

\section{Distribuição, probabilidade de ocorrência e período de retorno da erosividade das chuvas no Estado do Rio de Janeiro}

De acordo com as séries históricas trabalhadas, os valores de $\mathrm{EI}_{30}$ anual médio e $\mathrm{KE}>25$ no Estado do Rio de Janeiro variaram de 1.927,3 e 33,8 com desviopadrão de 472,9 e 8,1 em Farol de São Tomé (Campos); e a $15.805,8$ e 171,8 com desvio-padrão de 5.980,0 MJ $\mathrm{mm} \mathrm{ha}^{-1} \mathrm{~h}^{-1}$ ano $^{-1}$ e $63,1 \mathrm{MJ}^{-1}$ ano $^{-1}$ em Posto Garrafão, respectivamente (Quadros 2 e 3). As localidades sob influência das estações Conselheiro Paulino (Nova Friburgo) e Posto Garrafão (município de Magé), ambas na Mesorregião Centro Fluminense 


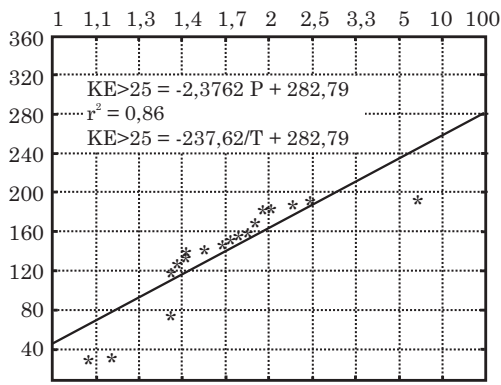

02243235 - Andorinhas

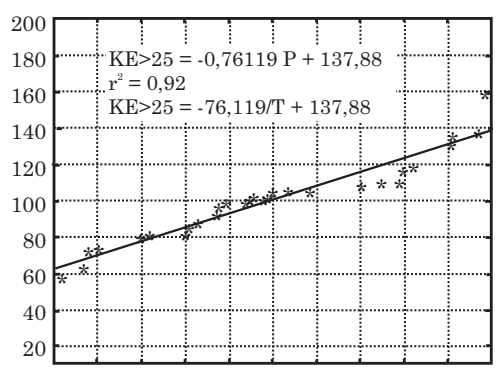

02243186 - Ecologia Agrícola

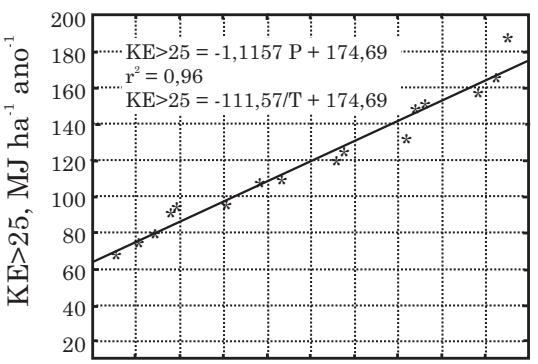

02242100 - Fazenda Coqueiro

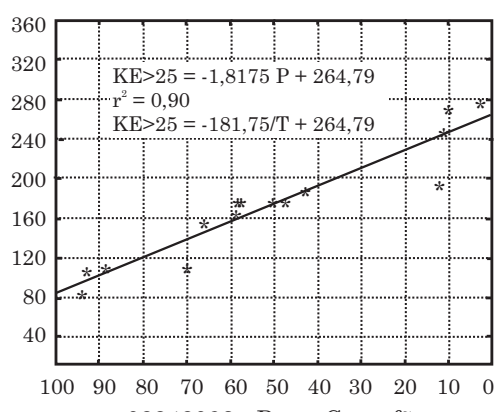
02242098 - Posto Garrafão
Período de retorno - T, anos

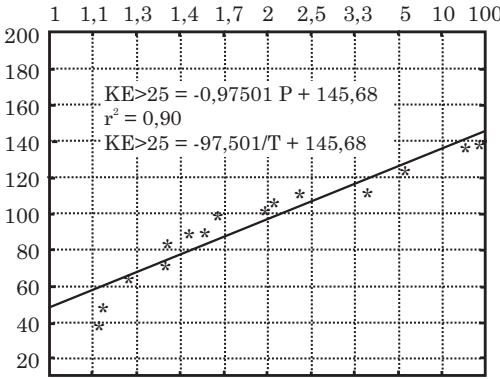

02242095 - Cachoeiras de Macacu

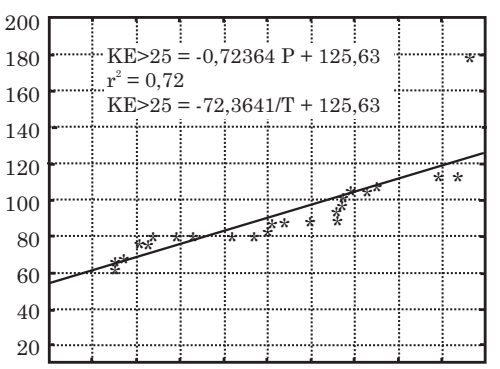

02243083 - Eletrobrás

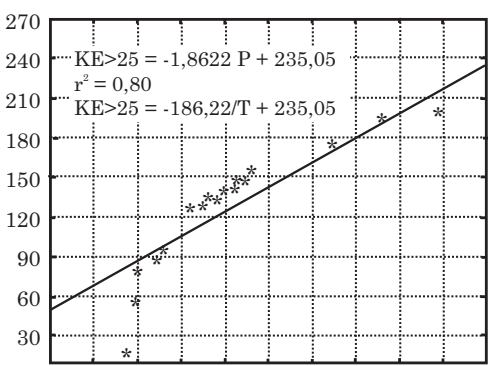

02242096 - Fazenda Santo Amaro

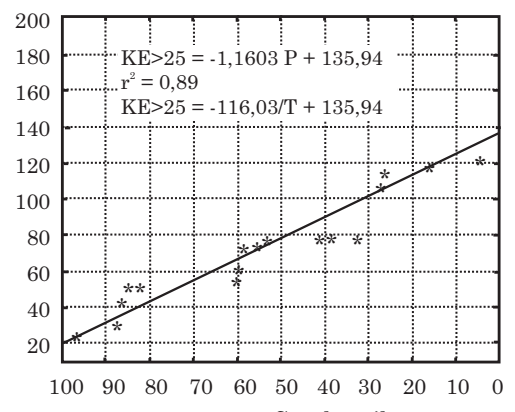
02242097 - Sambaetiba $\begin{array}{lllllllllll}1 & 1,1 & 1,3 & 1,4 & 1,7 & 2 & 2,5 & 3,3 & 5 & 10 & 100\end{array}$

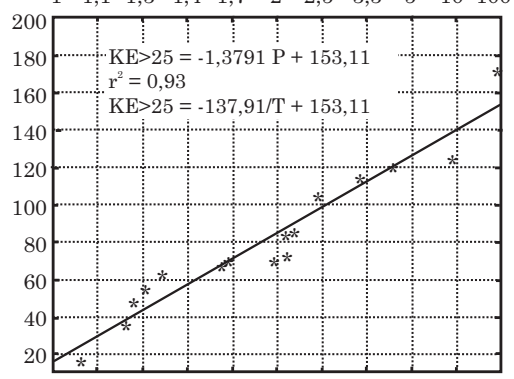

02243239 - Capela Mayrink

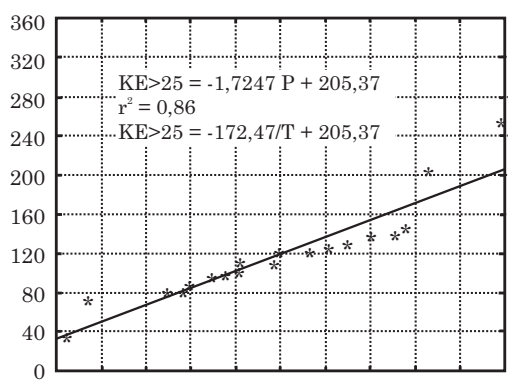

02242094 - Escola União

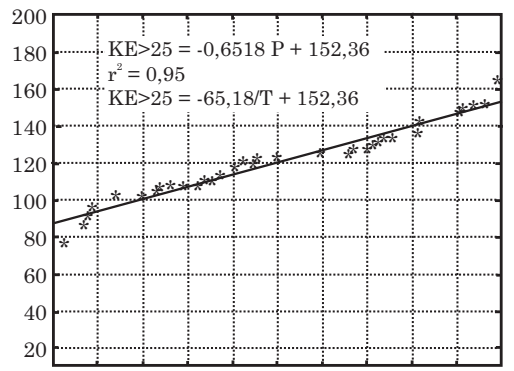

02242014 - Japuíba

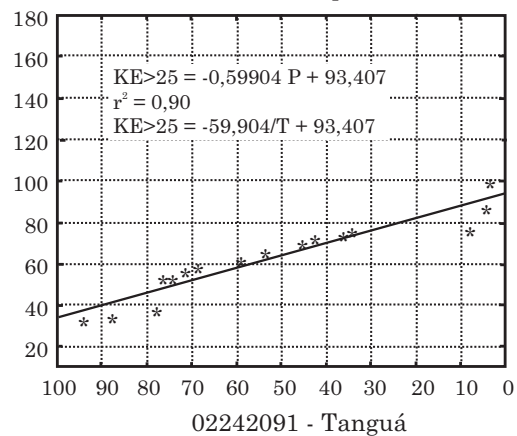

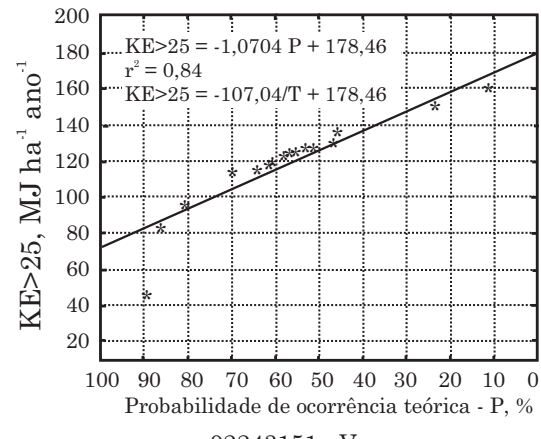

02243151 - Vassouras

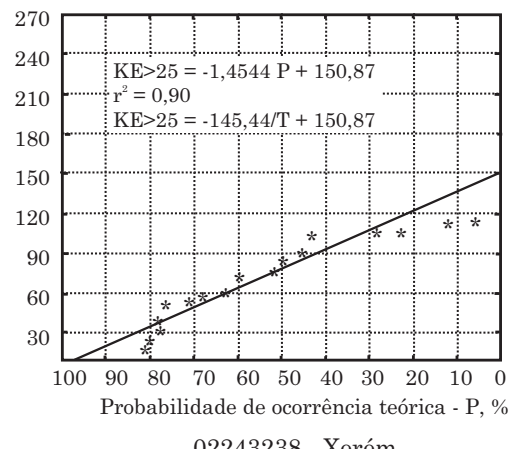

02243238 - Xerém

Figura 8. Distribuição da probabilidade de ocorrência (P) e do período de retorno (T) da erosividade das chuvas, medidos pelo índice KE > 25 anual, para estações localizadas na Mesorregião Metropolitana. 


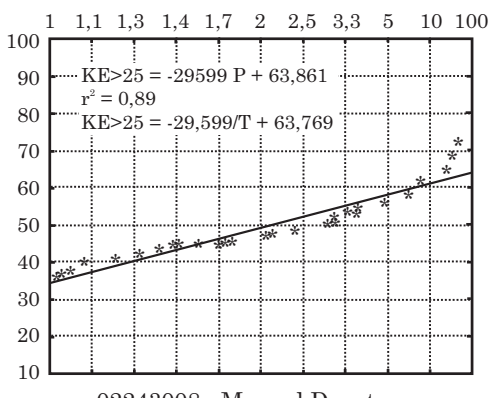

02243008 - Manuel Duarte

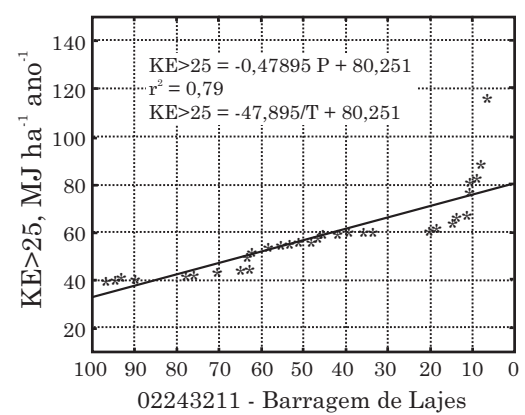

Período de retorno - $\mathrm{T}$, anos

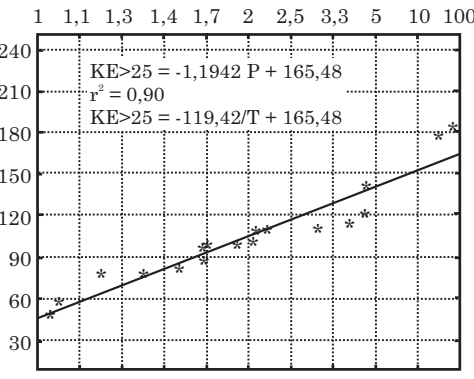

02243165 - Piraí

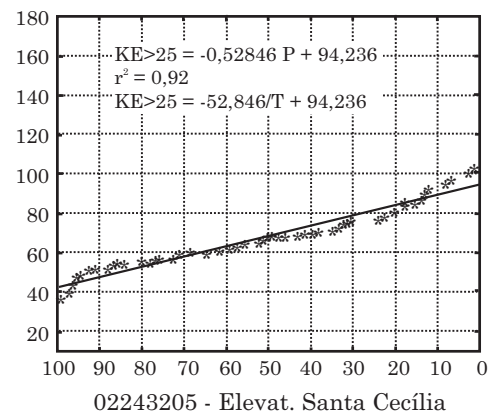

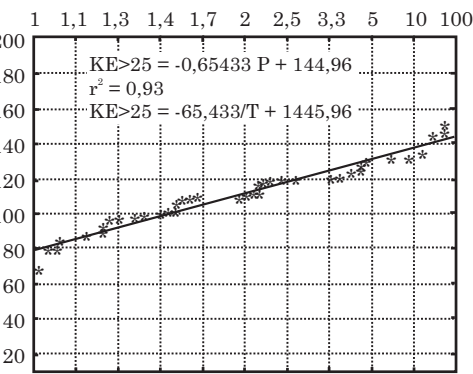

02244030 - Nhangapi

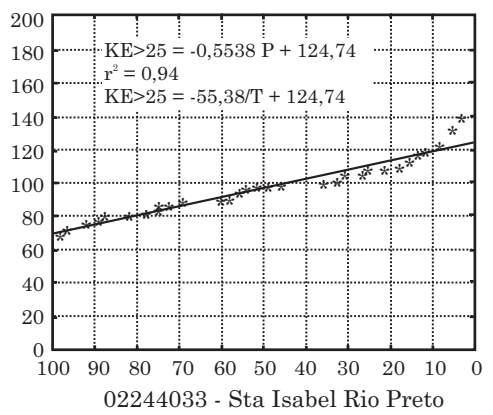

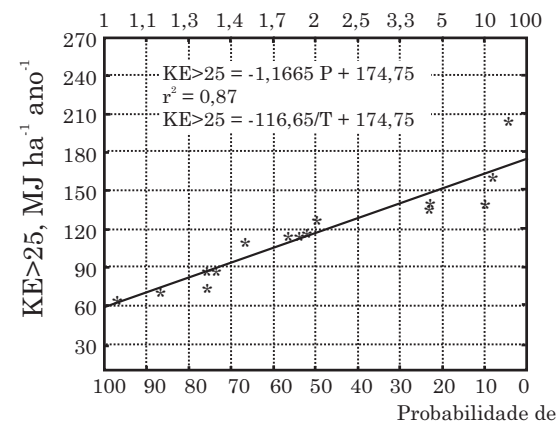

02244103 - Barragem de Tocos

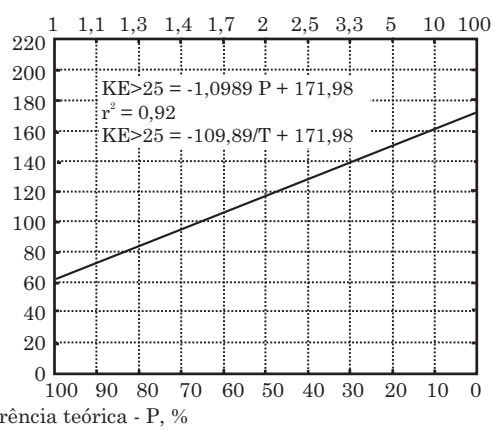

02344016 - Vila Mambucaba

Figura 9. Distribuição da probabilidade de ocorrência (P) e do período de retorno (T) da erosividade das chuvas, medidos pelo índice KE > 25 anual, para estações localizadas no Sul Fluminense.

(base IBGE), e da estação Vila Mambucaba, no município de Angra dos Reis, possuem o maior potencial erosivo das chuvas no Estado. De acordo com trabalho de André et al. (2008), esses maiores valores estão relacionados à localização dessas estações nas regiões homogêneas 3 (região serrana; no caso de Conselheiro Paulino) e 4 (encosta da serra do Mar e região Sul Fluminense), onde a precipitação pluvial média anual varia de 1.203,03 a $2.002,03 \mathrm{~mm}$, podendo, consequentemente, apresentar maior energia erosiva total.

No quadro 2, observa-se que a probabilidade de ocorrência teórica $(\mathrm{Pr})$ e o período de retorno $\mathrm{T}$ da erosividade média $\left(\mathrm{EI}_{30}\right)$ apresentaram valores próximos entre as estações estudadas, variando de 48,5 a $54,9 \%$ e de 1,8 a 2,1 anos, respectivamente. Utilizando a estação de Rio Mole como exemplo, podese afirmar que o valor de erosividade anual médio de 7.365,1 MJ mm ha-1 $\mathrm{h}^{-1}$ ano $^{-1}$ dessa localidade pode ser igualado ou ultrapassado pelo menos uma vez, em média, a cada 1,9 ano, com $52,9 \%$ de probabilidade.
Os valores de probabilidade de ocorrência do $\mathrm{EI}_{30}$ para as diferentes localidades do Rio de Janeiro foram um pouco mais elevados que os encontrados na literatura, enquanto os de período de retorno apresentaram-se ligeiramente menores que os encontrados em outras regiões do país, como nos trabalhos realizados por Carvalho et al. (1989), para Mococa, $\mathrm{SP}(\mathrm{Pr}=42 \% \mathrm{e}$ $\mathrm{T}=2,4$ anos); Moreti et al. (2003a), em São Manuel, SP ( $\operatorname{Pr}=42,9 \%$ e T = 2,3 anos); Mazurana et al. (2009), para Santa Rosa, RS (Pr $=43,3 \%$ e T $=2,3$ anos); Hickmann et al. (2008), para Uruguaiana, $\mathrm{RS}(\mathrm{Pr}=48 \%$ e T = 2,0 anos); e Evangelista et al. (2006), para Lavras, $\mathrm{MG}(\mathrm{Pr}=34 \%$ e $\mathrm{T}=2,9$ anos). Martins et al. (2010) encontraram para a região de tabuleiros costeiros do Espírito Santo Pr de 29,78\% e T de 3,4 anos.

Para a erosividade anual média medida pelo índice $\mathrm{KE}>25$, os resultados variaram de 48,8 a $54,4 \%$ e 1,8 a 2,1 anos para $\operatorname{Pr}$ e $\mathrm{T}$, respectivamente, semelhante ao observado para o índice $\mathrm{EI}_{30}$. Da mesma forma, esses valores foram relativamente menores que 
Quadro 2. Valores anuais médios, probabilidade de ocorrência e período de retorno da erosividade das chuvas $\left(\mathrm{EI}_{30}\right)$ e estatísticas simples para diferentes localidades no Estado do Rio de Janeiro

\begin{tabular}{|c|c|c|c|c|c|c|c|c|}
\hline \multirow{2}{*}{ Estação } & \multicolumn{6}{|c|}{$\mathrm{EI}_{30}\left(\mathrm{MJ} \mathrm{mm} \mathrm{ha}^{-1} \mathrm{~h}^{-1}\right.$ ano $\left.^{-1}\right)$} & \multirow{2}{*}{$\begin{array}{c}\text { TEI }_{30} \text { anual } \\
\text { médio }\end{array}$} & \multirow{2}{*}{$\begin{array}{c}\text { PrEI }_{30} \\
\text { anual médio }\end{array}$} \\
\hline & Tipo Eq. & $\begin{array}{c}\text { Anual médio } \\
\text { (fator R) }\end{array}$ & Mín. & Máx. & DP & $\mathrm{CV}(\%)$ & & \\
\hline \multicolumn{9}{|c|}{ Mesorregião Baixadas Litorâneas } \\
\hline Rio Mole & $\mathrm{Rc}$ & $7.365,1$ & $3.238,2$ & $10.499,4$ & $1.896,5$ & 25,7 & 1,9 & 52,9 \\
\hline Média & - & $7.365,1$ & - & - & - & - & - & - \\
\hline \multicolumn{9}{|c|}{ Mesorregião Centro Fluminense } \\
\hline Paquequer & $\mathrm{Rc}$ & $4.637,2$ & $1.369,1$ & $10.759,2$ & $2.365,1$ & 51,0 & 2,0 & 51,0 \\
\hline Cordeiro & $\mathrm{Rc}$ & $7.847,5$ & $4.010,0$ & $10.898,3$ & $1.614,7$ & 20,6 & 1,9 & 52,6 \\
\hline Usina Ilha dos Pombos & (1) & $5.652,7$ & $1.918,0$ & $9.511,0$ & $2.557,2$ & 45,2 & 1,9 & 51,8 \\
\hline Conselheiro Paulino & $\mathrm{Rc}$ & $9.100,5$ & $4.390,7$ & $15.811,1$ & $3.121,0$ & 34,3 & 1,9 & 51,7 \\
\hline Sta M. Madalena & $\mathrm{Rc}$ & $6.017,4$ & $4.324,4$ & $7.809,0$ & 997,3 & 16,6 & 2,0 & 51,1 \\
\hline Média & - & $6.651,1$ & - & - & - & - & - & - \\
\hline \multicolumn{9}{|c|}{ Mesorregião Metropolitana } \\
\hline Andorinhas & (1) & $13.653,5$ & $2.194,7$ & $2.8768,0$ & $5.980,0$ & 43,8 & 1,9 & 53,4 \\
\hline Cach. de Macacu & (1) & $7.962,0$ & $3.480,0$ & $12.975,0$ & $2.507,2$ & 31,5 & 1,9 & 52,9 \\
\hline Capela Mayrink & (1) & $9.331,6$ & $2.915,0$ & $1.9180,0$ & $3.605,3$ & 38,6 & 1,9 & 51,6 \\
\hline Ecologia Agrícola & $\mathrm{p}$ & $5.960,4$ & $3.350,6$ & $9.792,9$ & $1.278,3$ & 21,4 & 2,0 & 50,8 \\
\hline Eletrobrás & $\mathrm{Rc}$ & $5.988,6$ & $3.818,8$ & $11.993,9$ & $1.627,2$ & 27,2 & 2,0 & 48,8 \\
\hline Escola União & (1) & $10.077,9$ & $2.485,0$ & $25.903,0$ & $4.773,1$ & 47,4 & 2,0 & 50,9 \\
\hline Fazenda Coqueiro & (1) & $10.605,9$ & $5.901,2$ & $18.701,8$ & $3.398,5$ & 32,0 & 2,0 & 50,8 \\
\hline Fazenda Sto Amaro & (1) & $13.106,0$ & $1.418,5$ & $19.491,4$ & $4.090,1$ & 31,2 & 1,8 & 54,9 \\
\hline Japuíba & $\mathrm{p}$ & $9.452,4$ & $6.097,0$ & $12.915,4$ & $1.530,8$ & 16,2 & 2,0 & 50,7 \\
\hline Posto Garrafão & (1) & $15.805,8$ & $8.382,0$ & $25.829,0$ & $5.387,0$ & 34,1 & 2,0 & 50,0 \\
\hline Sambaetiba & (1) & $6.201,7$ & $3.207,0$ & $13.817,9$ & $2.578,4$ & 41,6 & 2,0 & 49,2 \\
\hline Tanguá & (1) & $5.292,5$ & $2.994,0$ & $8.492,0$ & $1.577,5$ & 29,8 & 2,0 & 50,7 \\
\hline Vassouras & $\mathrm{Rc}$ & $7.179,3$ & $2.713,2$ & $9.878,4$ & $1.599,5$ & 22,3 & 1,9 & 54,0 \\
\hline Xerém & $*$ & $6.719,4$ & $1.890,9$ & $19.285,0$ & $4.318,6$ & 64,3 & 2,0 & 50,2 \\
\hline Média & - & $9.095,5$ & - & - & - & - & - & - \\
\hline \multicolumn{9}{|c|}{ Mesorregião Norte Fluminense } \\
\hline Farol de São Tomé & $\mathrm{p}$ & $1.927,3$ & $1.302,8$ & $3.154,9$ & 472,9 & 24,5 & 2,0 & 49,7 \\
\hline Quiçamã & $\mathrm{Rc}$ & $6.257,3$ & $3.549,9$ & $12.393,5$ & $1.703,1$ & 27,2 & 2,0 & 49,3 \\
\hline Média & - & $4.092,3$ & - & - & - & - & - & - \\
\hline \multicolumn{9}{|c|}{ Mesorregião Sul Fluminense } \\
\hline Manuel Duarte & $\mathrm{p}$ & $5.128,3$ & $3.697,9$ & $7.258,3$ & 936,1 & 18,3 & 2,0 & 49,1 \\
\hline Piraí & $\mathrm{Rc}$ & $5.879,9$ & $2.769,8$ & $10.143,9$ & $1.937,7$ & 33,0 & 2,0 & 50,4 \\
\hline Nhangapi & $\mathrm{Rc}$ & $9.063,3$ & $5.172,2$ & $14.519,3$ & $1.803,6$ & 19,9 & 2,0 & 49,4 \\
\hline Barragem de Lajes & $\mathrm{p}$ & $4.882,0$ & $3.334,1$ & $7.681,1$ & $1.072,6$ & 22,0 & 2,1 & 48,5 \\
\hline Elevat. Santa Cecília & $\mathrm{p}$ & $5.417,8$ & $2.983,2$ & $9.519,0$ & $1.256,0$ & 23,2 & 2,0 & 49,8 \\
\hline Sta. Isa. Rio Preto & $\mathrm{p}$ & $7.613,4$ & $5.458,7$ & $10.949,6$ & $1.349,0$ & 17,7 & 2,0 & 49,7 \\
\hline Barragem de Tocos & (1) & $9.030,5$ & $4.204,0$ & $17.629,0$ & $3.426,3$ & 37,9 & 2,0 & 50,1 \\
\hline Vila Mambucaba & Rc & $12.800,9$ & $7.001,0$ & $20.266,7$ & $3.520,0$ & 27,5 & 2,0 & 50,0 \\
\hline Média & - & $7.477,0$ & - & - & - & - & - & - \\
\hline Mínimo & - & $1.927,3$ & $1.302,8$ & $3.154,9$ & 472,9 & 16,2 & 1,8 & 48,5 \\
\hline Máximo & - & $15.805,8$ & $8.382,0$ & $28.768,0$ & 59,80 & 64,3 & 2,1 & 54,9 \\
\hline Médio & - & $7.865,3$ & - & - & - & - & - & - \\
\hline
\end{tabular}

(1) Dados pluviográficos; $\mathrm{p}=$ precipitação mensal média; e Rc= coeficiente de chuva (Rc). 
Quadro 3. Valores anuais médios, período de retorno (T, anos) e probabilidade de ocorrência (P, \%) da erosividade das chuvas (KE > 25) e estatísticas simples para diferentes localidades no Estado do Rio de Janeiro

\begin{tabular}{|c|c|c|c|c|c|c|c|c|}
\hline \multirow{2}{*}{ Estação } & \multicolumn{5}{|c|}{ KE > $25\left(\right.$ MJ ha $^{-1}$ ano $\left.^{-1}\right)$} & \multirow{2}{*}{ CV $(\%)$} & \multirow{2}{*}{$\frac{T}{K E>25}$} & \multirow{2}{*}{$\frac{P}{\text { médio }}$} \\
\hline & Tipo Eq. & Médio & Mín. & Máx. & DP & & & \\
\hline \multicolumn{9}{|c|}{ Mesorregião Baixadas Litorâneas } \\
\hline Rio Mole & $\mathrm{Rc}$ & 84,0 & 37,0 & 119,0 & 21,8 & 25,9 & 1,9 & 52,9 \\
\hline Média & - & 84,0 & - & - & - & - & - & - \\
\hline \multicolumn{9}{|c|}{ Mesorregião Centro Fluminense } \\
\hline Paquequer & $\mathrm{Rc}$ & 80,2 & 26,3 & 258,9 & 50,2 & 62,6 & 2,0 & 49,4 \\
\hline Cordeiro & $\mathrm{p}$ & 92,9 & 46,0 & 139,0 & 22,3 & 24,0 & 1,9 & 51,9 \\
\hline Usina Ilha dos Pombos & (1) & 72,4 & 16,3 & 124,2 & 33,1 & 45,6 & 1,9 & 52,5 \\
\hline Conselheiro Paulino & $\mathrm{Rc}$ & 132,8 & 66,4 & 228,2 & 44,5 & 33,5 & 1,9 & 51,7 \\
\hline Sta M. Madalena & $\mathrm{Rc}$ & 89,7 & 64,0 & 113,0 & 14,4 & 16,1 & 2,0 & 51,2 \\
\hline Média & - & 93,6 & - & - & - & - & - & - \\
\hline \multicolumn{9}{|c|}{ Mesorregião Metropolitana } \\
\hline Andorinhas & (1) & 153,9 & 29,4 & 296,3 & 63,1 & 41,0 & 1,8 & 54,2 \\
\hline Cachoeiras de Macacu & (1) & 94,2 & 39,0 & 138,0 & 29,5 & 31,3 & 1,9 & 52,8 \\
\hline Capela Mayrink & (1) & 81,0 & 15,8 & 171,3 & 38,6 & 47,6 & 1,9 & 52,3 \\
\hline Eletrobrás & $\mathrm{Rc}$ & 90,3 & 58,0 & 176,8 & 23,4 & 25,9 & 2,1 & 48,8 \\
\hline Ecologia Agrícola & $\mathrm{Rc}$ & 99,2 & 57,0 & 158,0 & 22,3 & 22,4 & 2,0 & 50,8 \\
\hline Escola União & (1) & 117,5 & 33,9 & 253,9 & 48,4 & 41,2 & 2,0 & 51,0 \\
\hline Fazenda Coqueiro & (1) & 118,5 & 67,8 & 186,9 & 35,4 & 29,9 & 2,0 & 50,4 \\
\hline Fazenda Sto Amaro & (1) & 133,8 & 16,0 & 206,0 & 49,6 & 37,1 & 1,8 & 54,4 \\
\hline Japuíba & $\mathrm{p}$ & 119,3 & 77,0 & 164,0 & 19,6 & 16,4 & 2,0 & 50,7 \\
\hline Posto Garrafão & (1) & 171,8 & 83,0 & 276,0 & 56,5 & 32,9 & 2,0 & 51,1 \\
\hline Sambaetiba & (1) & 62,2 & 32,4 & 98,4 & 18,6 & 29,8 & 1,9 & 52,1 \\
\hline Tanguá & (1) & 120,7 & 46,0 & 167,0 & 27,2 & 22,5 & 1,9 & 53,9 \\
\hline Vassouras & $\mathrm{Rc}$ & 73,9 & 8,0 & 184,0 & 42,6 & 57,6 & 1,9 & 52,9 \\
\hline Xerém & (1) & 153,9 & 29,4 & 296,3 & 63,1 & 41,0 & 1,8 & 54,2 \\
\hline Média & - & 113,6 & - & - & - & - & - & - \\
\hline \multicolumn{9}{|c|}{ Mesorregião Norte Fluminense } \\
\hline Farol de São Tomé & $\mathrm{p}$ & 33,8 & 23,0 & 55,0 & 8,1 & 24,0 & 2,0 & 49,5 \\
\hline Quiçamã & $\mathrm{Rc}$ & 94,3 & 53,9 & 200,6 & 28,1 & 29,7 & 2,0 & 49,0 \\
\hline Média & - & 64,0 & - & - & - & - & - & - \\
\hline \multicolumn{9}{|c|}{ Mesorregião Sul Fluminense } \\
\hline Manuel Duarte & $\mathrm{p}$ & 49,4 & 36,0 & 72,0 & 9,1 & 18,4 & 2,1 & 48,9 \\
\hline Piraí & $\mathrm{Rc}$ & 105,4 & 50,0 & 184,0 & 35,1 & 33,3 & 2,0 & 50,3 \\
\hline Nhangapi & $\mathrm{p}$ & 111,7 & 67,4 & 165,6 & 19,0 & 17,0 & 2,0 & 50,8 \\
\hline Barragem de Lajes & $\mathrm{Rc}$ & 69,0 & 46,0 & 130,0 & 16,5 & 24,0 & 2,1 & 48,9 \\
\hline Elevat. Santa Cecília & $\mathrm{Rc}$ & 67,9 & 37,0 & 120,0 & 15,9 & 23,5 & 2,0 & 49,8 \\
\hline Sta. Is. Rio Preto & $\mathrm{p}$ & 97,2 & 69,0 & 138,0 & 17,2 & 17,7 & 2,0 & 49,7 \\
\hline Barragem de Tocos & (1) & 115,8 & 63,4 & 204,9 & 37,7 & 32,5 & 2,0 & 50,6 \\
\hline Vila Mambucaba & $\mathrm{Rc}$ & 117,0 & 61,0 & 190,0 & 33,6 & 28,7 & 2,0 & 50,0 \\
\hline Média & - & 91,7 & - & - & - & - & - & - \\
\hline Mín. & - & 33,8 & 8,0 & 55,0 & 8,1 & 16,1 & 1,8 & 48,8 \\
\hline Máx. & - & 171,8 & 83 & 296,3 & 63,1 & 62,6 & 2,1 & 54,4 \\
\hline Médio & - & 100,1 & - & - & - & - & - & - \\
\hline
\end{tabular}

(1) Dados pluviográficos; $\mathrm{p}=$ precipitação mensal média; e Rc= coeficiente de chuva (Rc). 
os obtidos por Carvalho et al. (1991) para a região de Mococa, SP, que apresentou Pr de $44 \%$ e T de 2,3 anos, para o KE > 25 médio anual (Quadros 2 e 3).

No quadro 4, são apresentados os índices de erosividade das chuvas associados aos períodos de retorno de 2, 5, 10, 20, 50 e 100 anos. Como podem ser observados, os valores de índices de erosividade esperados aumentaram em razão dos períodos de retorno. No entanto, de 50 para 100 anos, esse aumento foi relativamente pequeno, tanto para $\mathrm{EI}_{30}$ quanto para o índice $\mathrm{KE}>25$.

Para o período de retorno de dois anos, os valores de erosividade anual variaram de 1.923 a $15.807 \mathrm{MJ}$ $\mathrm{mm} \mathrm{ha}^{-1} \mathrm{~h}^{-1}$ ano $^{-1}$ para o índice $\mathrm{EI}_{30}$ e de 34 a $174 \mathrm{MJ}$ $\mathrm{ha}^{-1}$ ano $^{-1}$ para o índice KE $>25$ para as estações Farol de São Tomé e Posto Garrafão, respectivamente. Esses resultados foram semelhantes aos observados para a distribuição dos índices anuais médios de $\mathrm{EI}_{30}$ e $\mathrm{KE}>$ 25 nessas mesmas estações, em razão de a probabilidade de ocorrência desses índices serem coincidentemente de dois anos (Quadros 2 e 3).

No quadro 5, são apresentados os valores de $\mathrm{EI}_{30}$ associados aos períodos de retorno, obtidos por diferentes autores e localidades. Dentre as estações estudadas, Rio Mole, Cordeiro, Cachoeiras de Macacu, Vassouras e Santa Isabel do Rio Preto no Estado do Rio de Janeiro foram as que apresentaram resultados mais próximos a esses (Quadro 4). A variação do $\mathrm{EI}_{30}$ entre as localidades para os diferentes períodos de retorno é de certa forma semelhante (Quadro 5). No entanto, o mesmo não é observado quando se compara a variação ao longo dos mesmos períodos de retorno entre as estações dos Estados do Rio de Janeiro e São Paulo, apresentados no quadro 4, onde, nesse último, constatou-se maior variação da erosividade $\left(\mathrm{EI}_{30}\right)$.

Em relação ao $\mathrm{KE}>25$, os valores obtidos foram de $36,41,44,45,46,46 \mathrm{MJ} \mathrm{ha}^{-1}$ ano $^{-1}$, para a estação de Farol de São Tomé, e 174, 288, 247, 256, 261 e 263 $\mathrm{MJ}$ ha $^{-1}$ ano $^{-1}$, para a estação Posto Garrafão, para períodos de retorno de $2,5,10,20,50$ e 100 anos, respectivamente. Carvalho et al. (1991), realizando semelhante estudo para Mococa - SP, encontraram valores de $\mathrm{KE}>25$ de 136, 167, 187, 207 e $251 \mathrm{MJ}^{-1}$ ano $^{-1}$ para períodos de retorno de $2,5,10,20$ e 100 anos, respectivamente. Os valores encontrados por esses autores ficaram próximos para algumas

Quadro 4. Índices anuais médios de erosividade, $\mathrm{EI}_{30} \mathrm{e} \mathrm{KE}>25$ e associados a períodos de retorno (anos) para diferentes localidades no Estado do Rio de Janeiro

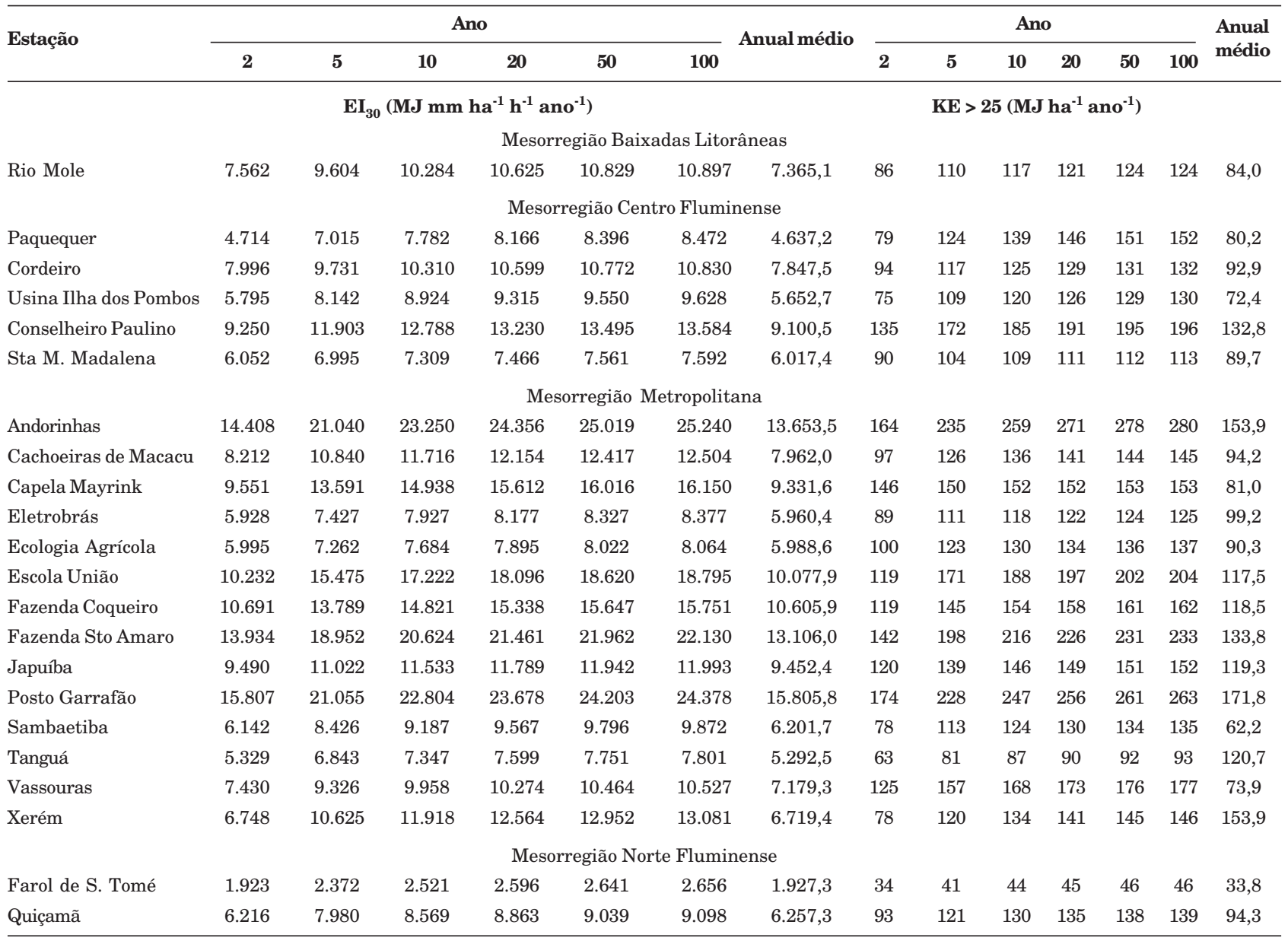


Quadro 5. Índice anual médio de erosividade $\left(\mathrm{EI}_{30}\right)$ para diferentes localidades e períodos de retorno

\begin{tabular}{|c|c|c|c|c|c|c|c|}
\hline \multirow{2}{*}{ Localidade } & \multicolumn{6}{|c|}{$\mathbf{T}$ (ano) } & \multirow{2}{*}{$\mathrm{EI}_{30}$ anual médio } \\
\hline & 2 & 5 & 10 & 20 & 50 & 100 & \\
\hline & \multicolumn{6}{|c|}{ MJ mm ha ${ }^{-1} h^{-1} a n o^{-1}$} & \\
\hline Mococa - $\mathrm{SP}^{(1)}$ & 7.355 & 9.151 & - & 11.455 & - & 14.062 & 7.747 \\
\hline Piraju - SP ${ }^{(2)}$ & 6.696 & 8.730 & 10.076 & 11.367 & 13.039 & 14.292 & 7.074 \\
\hline Teodoro Sampaio - SP ${ }^{(3)}$ & 6.831 & 8.666 & 9.877 & 11.046 & 12.546 & 13.675 & 7.172 \\
\hline São Manuel - SPP & 7.216 & 8.675 & 9.641 & 10.568 & 11.768 & 12.667 & 7.487 \\
\hline Pedrinhas Paulista - $\mathrm{SP}^{(5)}$ & 7.404 & 8.833 & 9.779 & 10.686 & 11.860 & 12.740 & 7.670 \\
\hline Lavras - $\mathrm{MG}^{(6)}$ & 5.400 & 7.000 & 8.000 & 8.800 & 9.900 & 10.500 & 5.403 \\
\hline Cuiabá - $\mathrm{MT}^{(7)}$ & 8.442 & 10.426 & 11.739 & 12.999 & 14.630 & 15.852 & 8810 \\
\hline
\end{tabular}

(1) Carvalho et al. (1989); (2) Roque et al. (2001); ${ }^{(3)}$ Colodro et al. (2002); ${ }^{(4)}$ Moreti et al. (2003a); (5) Moreti et al. (2003b); (6) Evangelista et al. (2006); e ${ }^{(7)}$ Almeida et al. (2011).

localidades da mesorregião metropolitana, com exceção para o período de retorno de 100 anos.

\section{Distribuição espacial da erosividade associada aos diferentes períodos de retorno}

Conforme se observa nos mapas (Figuras 10 e 11), independentemente do período de retorno, os locais que apresentaram maiores valores de erosividade estão localizados na mesorregião Metropolitana e em partes da Sul e Centro Fluminense, com valores de $\mathrm{EI}_{30}$ acima de $9.000 \mathrm{MJ} \mathrm{mm} \mathrm{ha-1} \mathrm{h}^{-1} \mathrm{ano}^{-1}$, para o período de retorno de dois anos (Figura 10a).

Analisando o período de retorno de dois anos, que é o tempo em que a erosividade anual média ou fator $\mathrm{R}$ da USLE pode ser igualado ou superado pelo menos uma vez em média, a maior parte do Estado do Rio de Janeiro apresentou-se na faixa de erosividade de 7.000 a $9.000 \mathrm{MJ} \mathrm{mm} \mathrm{ha}{ }^{-1} \mathrm{~h}^{-1} \mathrm{ano}^{-1}$. Excetuou-se dessa faixa de erosividade a mesorregião Norte Fluminense quase por inteira e partes das mesorregiões Metropolitana e Sul Fluminense, sendo, a primeira, onde ocorrem as áreas com menor índice de erosividade (partes dos municípios de Campos e São João da Barra, conforme divisão de municípios do IBGE) e, o contrário, nas outras duas. Apesar da diferença entre os métodos de mapeamento, a erosividade das chuvas associadas ao período de retorno de dois anos apresenta razoável semelhança aos resultados do estudo de espacialização da erosividade anual média no Estado do Rio de Janeiro, realizado por Montebeller et al. (2007). Assim como neste trabalho, esses autores já haviam constatado que a erosividade diminui da mesorrregião Sul Fluminense (identificada como Baía de Ilha Grande), para o sentido Norte Fluminense.

Esses menores valores de erosividade corroboram com trabalho de André et al. (2008), os quais classificaram essa região climaticamente homogênea como a de menor precipitação total anual no Estado. Segundo os autores, a explicação para isso é que, tanto a região norte quanto a noroeste estão situadas em grande baixada a sotavento da serra do Mar, o que contribui para a compressão na baixa troposfera em razão das entradas de escoamento de sudoeste, sendo os principais mecanismos de geração de nuvens nessas regiões.

Ainda no período de retorno de dois anos (Figura 10b), verificou-se que a classe de erosividade de 9.000 a $11.000 \mathrm{MJ} \mathrm{mm} \mathrm{ha}^{-1} \mathrm{~h}^{-1} \mathrm{ano}^{-1}$ de forma geral é esperada na parte central da mesorregião Metropolitana, acompanhando a divisa com a mesorregião Centro-fluminense. Essa última chega a abranger parte dos municípios de Paraíba do Sul, Areal (quase todo), Três Rios, Sumidouro, Nova Friburgo, pequena porção do município de Silva Jardim (Baixadas Litorâneas), próxima aos limites de Nova Friburgo e Cachoeiras de Macacu. Essa mesma classe de erosividade ocorre também em Angra dos Reis, na mesorregião Sul-Fluminense. O comportamento de distribuição espacial dessa amplitude de erosividade está coerente com a classificação das regiões climatologicamente homogêneas 3 e 4 do estudo de André et al. (2008), os quais afirmaram ser locais onde ocorrem precipitações elevadas em razão da conformação do relevo e da maior umidade do ar vinda do oceano sentido sudoeste.

Em relação à distribuição espacial dos locais de maior erosividade no Estado, cor mais escura nos mapas, ocorre em parte nos municípios de Magé e Guapimirim, bem como na região próxima à divisa com Petrópolis e Teresópolis. Incide também em área relativamente pequena no município de Cachoeiras de Macacu e divisa com Nova Friburgo nas mesorregiões Metropolitana e Centro Fluminense, assim como em porção dos municípios de Parati na região Sul Fluminense. Isso está relacionado à proximidade de regiões de altas taxas de precipitação pluviométrica, resultante de fatores orográficos apontados por André et al. (2008), principalmente no caso de parte da área do município de Cachoeiras de Macacu, coincidindo com a região homogênea um (1) dos autores, considerada a de mais alta precipitação no Estado. Em complemento, Mello et al. (2007) 
destacam a influência da zona de convergência do Atlântico Sul, de ocorrência comum no Sudeste brasileiro, combinada com sistemas atmosféricos ciclônicos, que intensificam os efeitos orográficos e de convecção atmosférica, sendo, esse último, gerado por maiores temperaturas médias.

De modo geral, a maior variação da distribuição da erosividade nos mapas tende a ocorrer no período de retorno de dois para cinco anos, evidenciado pelo aumento do número de classes de erosividade, em detrimento ao aumento ou redução de área de cada classe. No período de retorno de cinco anos, observouse, na figura $10 \mathrm{~b}$, que as áreas referentes aos maiores valores de erosividade pouco se alteraram no mapa. No entanto, surgiram novas classes de erosividade com valores intermediários.

Analisando a erosividade anual média associada aos períodos de retorno de cinco anos em diante, constatouse que o aumento do número de classes é pequeno, bem como a área de cada classe. Dessa forma, a variação da erosividade está mais relacionada ao aumento do período de retorno que da distribuição espacial.

Em relação ao índice $\mathrm{KE}>25$, verificou-se, de modo geral, que o comportamento da erosividade associado aos períodos de retorno seguiu a mesma tendência ao observado para o índice $\mathrm{EI}_{30}$ (Figura 10). Levando em conta que o índice $\mathrm{KE}>25$ considera apenas os segmentos das chuvas com intensidade igual ou superior a $25 \mathrm{~mm} \mathrm{~h}^{-1}$, é de se esperar que, nos locais de maior erosividade anual média, ocorra maior percentual de precipitações mais intensas e com maior potencial erosivo.

Os mapas (Figuras 10 e 11) aqui apresentados têm por objetivo oferecer visão geral do comportamento da erosividade das chuvas, associada aos diferentes períodos de retorno no Estado. Para informações mais precisas será necessário, em estudos futuros, introduzir mais estações, principalmente nas mesorregiões Norte
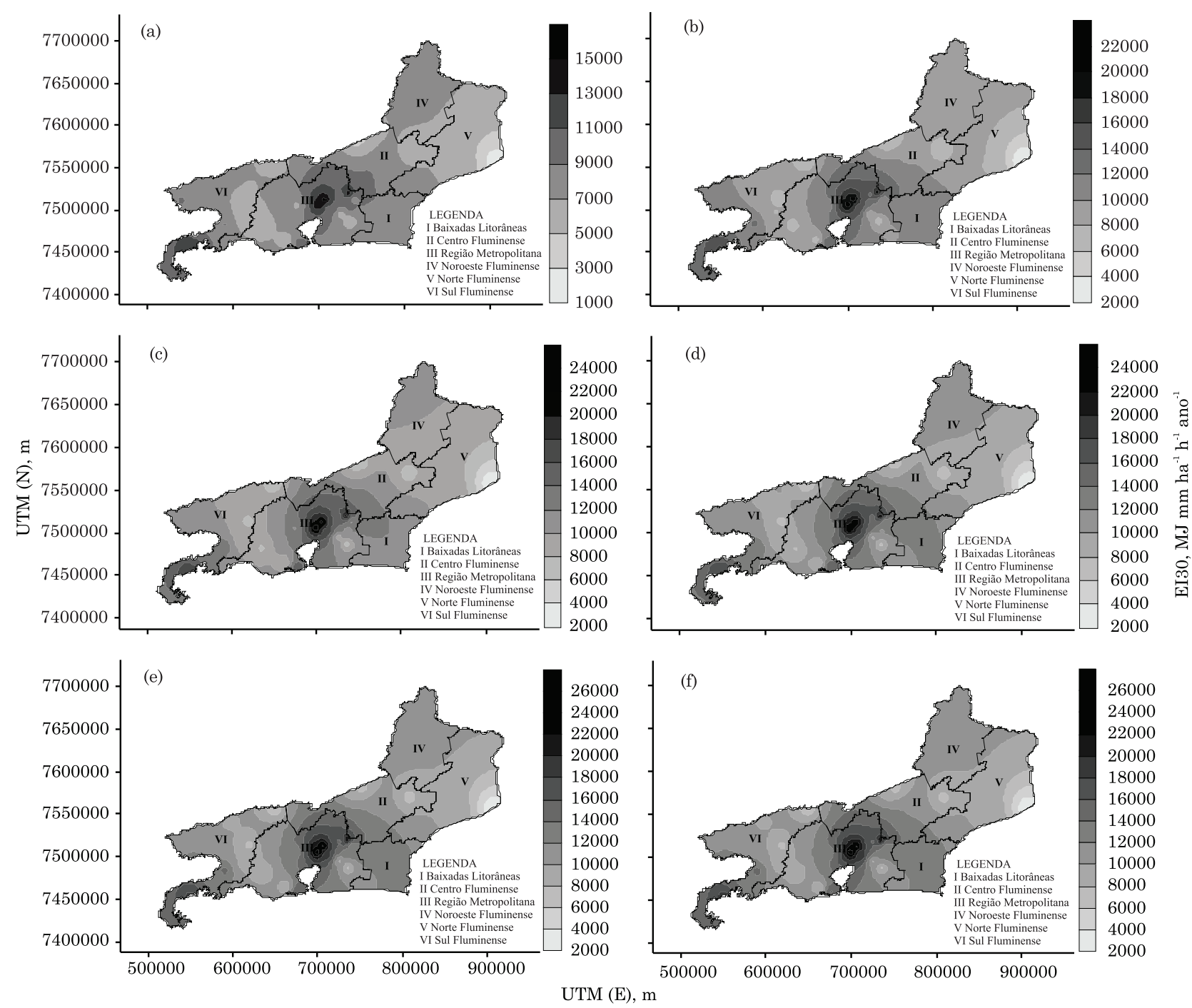

Figura 10. Mapas de iso-ocorrência da erosividade das chuvas $\left(\mathrm{EI}_{30}\right)$ associada aos períodos de retorno 2 (a), 5 (b), 10 (c), 20 (d), 50 (e) e 100 (f) anos. 

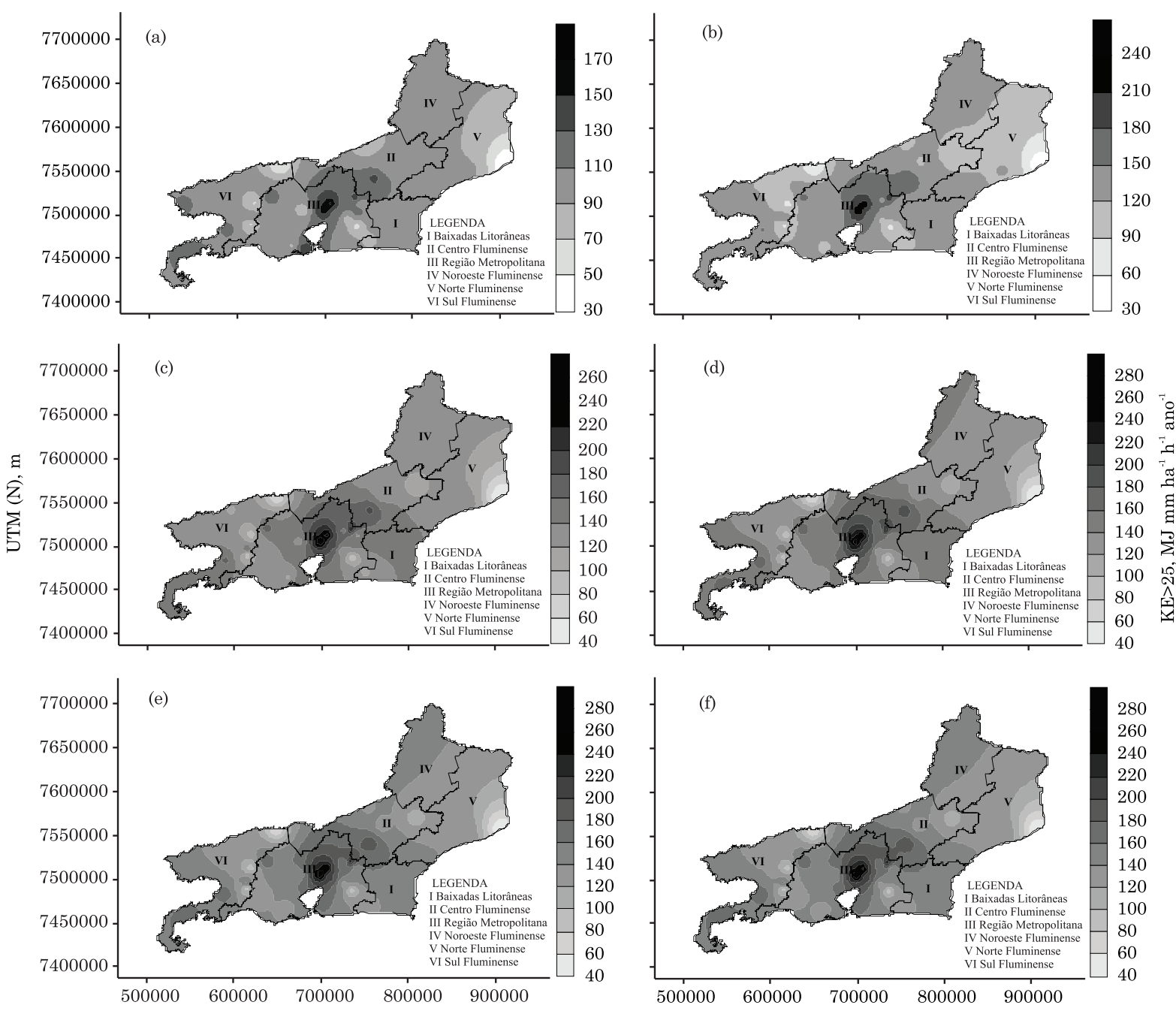

Figura 11. Mapas de iso-ocorrência da erosividade das chuvas (KE > 25) associada aos períodos de retorno de: 2 (a), 5 (b), 10 (c), 20 (d), 50 (e) e 100 (f) anos.

e Noroeste, além de utilizarem-se técnicas que levem em conta a dependência espacial, como os métodos geoestatísticos (krigagem).

\section{CONCLUSÕES}

1. A erosividade anual média $\left(\mathrm{EI}_{30}\right)$ ou fator $\mathrm{R}$ da USLE para qualquer localidade no Estado do Rio de Janeiro pode ser igualada ou superada pelo menos uma vez, em média, em um período de 1,8 a 2,1 anos, com faixa de 48,5 a $54,9 \%$ de probabilidade de ocorrência teórica.

2. As condições do estudo realizado fizeram com que fosse possível identificar de oito a 12 regiões homogêneas quanto à distribuição espacial da erosividade, associada aos períodos de retorno de dois para 100 anos no Estado do Rio de Janeiro.

3. A maior variação espacial (número de classes e área de cada classe) da erosividade ocorre para períodos de retorno de dois para cinco anos e para maiores valores de período de retorno, a variação está mais associada à magnitude das classes de erosividade. Há tendência de menor variação espacial (área) da erosividade nas partes mais planas do Estado, acompanhando menores valores de erosividade como ocorre nas Mesorregiões Norte, Noroeste e Baixadas Litorâneas.

4. Os índices de erosividade $\mathrm{EI}_{30}$ e $\mathrm{KE}>25$ apresentaram comportamento semelhante quanto à distribuição espacial da erosividade no Estado.

\section{AGRADECIMENTOS}

Às entidades ANA, INMET, LIGHT, DNOS, SERLA (atual INEA), pela disponibilidade dos dados pluviográficos; e ANA/Hidroweb, pelos dados pluviométricos. Ao professor Joseph Kalil Khoury Júnior (UFV), pela ajuda no uso do software MatLab. 
Ao prof. Adão Evangelista (UFG), pelo auxílio em Distribuição de Probabilidade Log-Normal. Ao Curso de Pós-Graduação em Agronomia - Ciência do Solo, pela oportunidade de realizar este trabalho por meio da tese. À CAPES, pelo indispensável auxílio financeiro (bolsa), durante os dois primeiros anos do Curso de doutorado.

\section{LITERATURA CITADA}

AGÊNCIA NACIONAL DE ÁGUAS - ANA. Inventário das estações pluviométricas. 2.ed. Brasília, ANA/SGRH, 2009. 495p.

ALMEIDA, C.O.S.; AMORIMN, R.S.S.; COUTO, E.G.; ELTZ, F.L.F. \& BORGES, L.E.C. Potencial erosivo da chuva de Cuiabá-MT: Distribuição e correlação com a precipitação pluviométrica. R. Bras. Eng. Agric. Amb., 15:178-184, 2011.

ANDRÉ, R.G.B.; MARQUES, V.S.; PINHEIRO, F.M.A. \& FERRAUDO, A.S. Identificação de regiões pluviometricamente homogêneas no Estado do Rio de Janeiro utilizando-se valores mensais. R. Bras. Meteorol., 23:501-509, 2008.

BERTONI, J. \& LOMBARDI NETO, F. Conservação do solo. 2.ed. São Paulo, Ícone, 1990. 355p.

CABEDA, M.S.V. Computation of storm EI value. West Lafayette, Purdue University, 1976. 6p. (Não publicado)

CARVALHO, D.F.; MACHADO, R.L.; EVANGELISTA, A.W.P.; KHOURY JÚNIOR, J.K.; SILVA, L.D.B. Distribuição, probabilidade de ocorrência e período de retorno dos índices de erosividade $\mathrm{EI}_{30}$ e $\mathrm{KE}>25 \mathrm{em}$ Seropédica - RJ. Eng. Agríc., 30:245-252, 2010.

CARVALHO, D.F.; MONTEBELLER, C.A.; FRANCO, E.M.; VALCARCEL, R. \& BERTOL, I. Padrões de precipitação e índices de erosividade para as chuvas de Seropédica e Nova Friburgo-RJ. R. Bras. Eng. Agric. Amb., 9:7-14, 2005.

CARVALHO, M.P.; LOMBARDI NETO, F.; VASQUES FILHO, J. \& CATANEO, A. Índices de erosividade da chuva correlacionados com as perdas de um Podzólico VermelhoAmarelo Eutrófico textura argilosa/muito argilosa de Mococa (SP): Primeira aproximação do fator erodibilidade dos solos. R. Bras. Ci. Solo, 13:237-242, 1989.

CARVALHO, M.P.; LOMBARDI NETO, F.; VASQUES FILHO, J. \& CATÂNEO, A. Correlação entre o índice de erosividade $\mathrm{EI}_{30}$ médio mensal e o coeficiente de chuva do município de Mococa-SP. Científica, 19:1-7, 1991.

CASSOL, E.A.; ELTZ, F.L.F.; MARTINS, D.; LEMOS, A.M.; LIMA, V.S. \& BUENO, A.C. Erosividade, padrões hidrológicos, período de retorno e probabilidade de ocorrência das chuvas em São Borja, RS. R. Bras. Ci. Solo, 32:1239-1251, 2008.

COLODRO, G.; CARVALHO, M.P.; ROQUE, C.G. \& PRADO, R.M. Erosividade da chuva: Distribuição e correlação com a precipitação pluviométrica de Teodoro Sampaio (SP). R. Bras. Ci. Solo, 26:809-818, 2002.
DIAS, A.S. \& SILVA, J.R.C. A erosividade das chuvas em Fortaleza (CE). I - Distribuição, probabilidade de ocorrência e período de retorno - $1^{\mathrm{a}}$ aproximação. R. Bras. Ci. Solo, 27:335-345, 2003.

DULEY, F.L. Surface factor affecting the rate of intake of water by soils. Soil Sci. Soc. Am. Proc., 4:60-64, 1939.

ELLISON, W.D. Soil erosion studies - part II: Soil detachment hazard by raindrop splash. Agric. Eng., 28:197-201, 1947.

EVANGELISTA, A.W.P.; CARVALHO, L.G.; DANTAS, A.A.A.D. \& BERNARDINO, D.T. Potencial erosivo das chuvas em Lavras, MG: Distribuição, probabilidade de ocorrência e período de retorno. Irriga, 11:1-11, 2006.

FOURNIER, F. The effect climatics on soil erosion estimates for solids transported in suspension in runoff. [S.L.], Association Hydrologig Int. Public., 1956. v.38. 6p.

GONÇALVES, F.A. Erosividade das chuvas no Estado do Rio de Janeiro. Viçosa, MG, Universidade Federal de Viçosa, 2002. 90p. (Dissertação de Mestrado)

GONÇALVES, F.A.; SILVA, D.D.; PRUSKI, F.F.; CARVALHO, D.F. \& CRUZ, E. Índices e espacialização da erosividade das chuvas para o Estado do Rio de Janeiro. R. Bras. Eng. Agric. Amb., 10:269-276, 2006.

GOTWAY, C.A.; FERGUSON, R.B.; HERGERT, G.W. \& PETERSON, T.A. Comparison of kriging and inversedistance methods for mapping soil parameters. Soil Sci. Soc. Am. J., 60:1237-1247, 1996.

HICKMANN, C.; ELTZ, F.L.F.; CASSOL, E.A. \& COGO, C.M. Erosividade das chuvas em Uruguaiana, RS, determinadas pelo índice $\mathrm{EI}_{30}$, com base no período de 1963 a 1991. R. Bras. Ci. Solo, 32:825-831, 2008.

HUDSON, N.W. Soil conservation. 3.ed. Ithaca, Cornell University Press, 1995. 324p.

HUDSON, N.W. Soil Conservation. Ithaca, Cornell University Press, 1973. 320p.

LAL, R. Soil erosion on alfisols in western Nigeria. III. Effects of rainfall characteristics. Geoderma, 16:389-401, 1976.

LOMBARDI NETO, F. Rainfall erosivity - its distribution and relationship with soil loss at Campinas, Brazil. West Lafayette, Purdue University, 1977. 53p. (Dissertação de Mestrado)

MARQUES, J.J.G.S.M.; ALVARENGA, R.C.; CURI, N.; SANTANA, D.P. \& SILVA, M.L.N. Índices de erosividade da chuva, perdas de solo e fator erodibilidade para dois solos da região dos cerrados - primeira aproximação. R. Bras. Ci. Solo, 21:427-434, 1997.

MARTINS, S.G.; AVANZI, J.C.; SILVA, M.L.N.; CURI, N.; NORTON, L.D. \& FONSECA, S. Rainfall erosivity and rainfall return period in the experimental watershed of Aracruz, in the coastal plain of Espirito Santo, Brazil. R. Bras. Ci. Solo, 34:999-1004, 2010.

MAZURANA, J.; CASSOL, E.A.; SANTOS, L.C.; ELTZ, F.L.F. \& BUENO, A.C. Erosividade, padrões hidrológicos e período de retorno das chuvas erosivas de Santa Rosa (RS). R. Bras. Eng. Agric. Amb., 13:975-983, 2009. 
MELLO, C.R.; SÁ, M.A.C.; CURI, N.; MELLO, J.M.; VIOLA, M.R. \& SILVA, A.M. Erosividade mensal e anual da chuva no Estado de Minas Gerais. Pesq. Agropec. Bras., 42:537$545,2007$.

MONTEBELLER, C.A. Variabilidade espacial do potencial erosivo das chuvas no Estado do Rio de Janeiro. Seropédica, Universidade Federal Rural do Rio de Janeiro, 2005. 103p. (Dissertação de Mestrado)

MONTEBELLER, C.A.; CEDDIA, M.B.; CARVALHO, D.F.; VIEIRA, S.R. \& FRANCO, E.M. Variabilidade espacial do potencial erosivo das chuvas no Estado do Rio de Janeiro. Eng. Agríc., 27:426-435, 2007.

MORETI, D.; CARVALHO, M.P.; MANNIGEL, A.R. \& MEDEIROS, L.R. Importantes características de chuva para a conservação do solo e da água no município de São Manuel (SP). R. Bras. Ci. Solo, 27:713-725, 2003a.

MORETI, D.; MANNIGEL, A. R.; CARVALHO, M. P. Fator erosividade da chuva para o município de Pedrinhas Paulista, Estado de São Paulo. Acta Sci. Agron., 25:137145. $2003 \mathrm{~b}$.

PEÑALVA BAZZANO, M.G.P.; ELTZ, F.L.F. \& CASSOL, E.A. Erosividade e características hidrológicas das chuvas de Rio Grande (RS). R. Bras. Ci. Solo, 34:235-244, 2010.

PEÑALVA BAZZANO, M.G.; ELTZ, F.L.F. \& CASSOL, E.A. Erosividade, coeficiente de chuva, padrões e período de retorno das chuvas de Quaraí, RS. R. Bras. Ci. Solo, 31:1205-1217, 2007.
ROQUE, C.G.; CARVALHO, M.P. \& PRADO, R.M. Fator erosividade da chuva de Piraju (SP): distribuição, probabilidade de ocorrência, período de retorno e correlação com o coeficiente da chuva. R. Bras. Ci. Solo, 25:147-156, 2001.

RUFINO, R.L.; BISCAIA, R.C.M. \& MERTEN, G.H. Determinação do potencial erosivo da chuva do Estado do Paraná através da pluviometria: Terceira aproximação. R. Bras. Ci. Solo, 17:439-444, 1993.

SILVA, C.R.J. \& DIAS, S.A. A erosividade das chuvas em Fortaleza, CE. II - Correlação com o coeficiente de chuva e atualização do fator R no período de 1962 a 2000 . R. Bras. Ci. Solo, 27:347-354, 2003.

SILVA, M.L.N.; FREITAS, P.L.; BLANCANEAUX, P. \& CURI, N. Índices de erosividade das chuvas da região de Goiânia, GO. Pesq. Agropec. Bras., 32:977-985, 1997.

VILLELA, S.M. \& MATOS, A. Hidrologia aplicada. São Paulo, McGraw-Hill, 1975. 245p.

WISCHMEIER, W.H. \& SMITH, D.D. Predicting rainfall-erosion losses, a guide to conservation planning. Washington, USDA, 1978. 58p. (Agriculture Handbook, 537)

WISCHMEIER, W.H. A rainfall erosion index for a universal soil loss equation. Soil Sci. Am. Proc., 20:246-249, 1959.

WISCHMEIER, W.H. \& SMITH, D.D. Rainfall energy and its relationships to soil loss. Trans. Am. Geophys. Union, 39:285-291, 1958. 